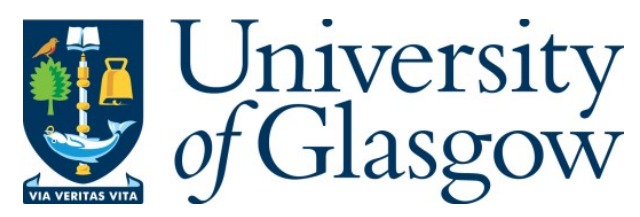

Mousavi, S. M., Kamali, R., Sotoudeh, F., Karimi, N. and Jeung, I.-S. (2020) Numerical investigation of the effects of swirling hot co-flow on MILD combustion of a hydrogenmethane blend. Journal of Energy Resources Technology, 142(11), 112301.

(doi: $\underline{10.1115 / 1.4047251)}$

There may be differences between this version and the published version. You are advised to consult the publisher's version if you wish to cite from it.

http://eprints.gla.ac.uk/208992/

Deposited on: 29 January 2020

Enlighten - Research publications by members of the University of Glasgow http://eprints.gla.ac.uk 


\section{American Society of Mechanical Engineers}

SETTING THE STANDARD

\section{ASME Accepted Manuscript Repository}

\section{Institutional Repository Cover Sheet}

$\overline{\text { First }}$ Last

Numerical investigation of the effects of swirling hot co-flow on MILD combustion of a hydrogenASME Paper Title: methane blend

Authors: $\quad$ Seyed Mahmood Mousavi, Reza Kamali, Freshteh Sotoudeh, Nader Karimi, In-Seuck Jeung

ASME Journal Title: Journal of Energy Resources Technology

Volume/Issue 142(11)

Date of Publication (VOR* Online) June 9, 2020

ASME Digital Collection URL: https://asmedigitalcollection.asme.org/energyresources/article-abstract/142/11/112301/1083928/

DOI:

*VOR (version of record) 


\title{
Numerical investigation of the effects of swirling hot co-flow on MILD combustion of a hydrogen-methane blend
}

Seyed Mahmood Mousavi ${ }^{1}$, Reza Kamali ${ }^{1}$, Freshteh Sotoudeh ${ }^{1}$, Nader Karimi ${ }^{2}$, In-Seuck Jeung ${ }^{3}$

${ }^{1}$ School of Mechanical Engineering, Shiraz University, Shiraz, 71936-16548, Iran

${ }^{2}$ School of Engineering, University of Glasgow, Glasgow, G128QQ, United Kingdom

${ }^{3}$ Department of Aerospace Engineering, Seoul National University, Seoul, 08826, Republic of

Korea

\begin{abstract}
This paper examines the effects of swirl hot co-flow on the combustion behavior of a MILD burner fueled by a mixture of methane and hydrogen. Towards this goal, realizable k- $\varepsilon$ turbulence model, GRI. 2.11 reaction mechanism and the discrete ordinates radiation model are incorporated into a computational modelling of the reactive flow. The numerical results are, first, favorably compared against the existing experimental data. Subsequently, a number of swirl co-flows are implemented, and structures of the resultant reactive flows are investigated systematically. The outcomes indicate that increasing the swirl velocity leads to the reduction of ignition delay and significantly enhances the reaction completion. Analysis of the spatial distribution of hydroxyl and formyl $(\mathrm{OH}$ and $\mathrm{HCO}$ ) radicals reveals that swirling MILD combustion radially extends the reaction zone in comparison with the conventional MILD combustion. Yet, it reduces the length of the reactive region and allows for occurrence of heat release in a shorter axial distance from the outlet fuel nozzle. Further, addition of swirl reduces the production of carbon monoxide through its influences upon flow temperature and generation of formyl radical. However, it is found that swirling hot coflow intensifies $\mathrm{NO}_{\mathrm{x}}$ emissions by strengthening of prompt and thermal mechanisms of $\mathrm{NO}_{\mathrm{x}}$ production. Reducing the temperature of the recycled flue gas is deemed to be an effective way of resolving this issue.
\end{abstract}


Keywords: Jet-in-Hot Co-flow burner; MILD Combustion; Swirl Mild Combustion; Hydrogenmethane blend; $\mathrm{NO}_{\mathrm{x}}$ and $\mathrm{CO}$ emissions.

\begin{tabular}{|c|c|c|c|}
\hline \multicolumn{4}{|c|}{ Nomenclature } \\
\hline \multicolumn{2}{|c|}{ Symbols } & $Y_{i}^{*}$ & $\begin{array}{l}\text { Fine-scale species mass fraction after } \\
\text { reacting over the time } \tau^{*}\end{array}$ \\
\hline A & pre-exponential factor & $\mathrm{Z}$ & mixture fraction \\
\hline$C_{\xi}$ & volume fraction constant & $W_{j}$ & atomic mass for element $j$ \\
\hline$C_{\tau}$ & time scale constant & \multicolumn{2}{|l|}{ Greek letters } \\
\hline $\mathrm{E}$ & energy & $\varepsilon$ & rate of dissipation of turbulence energy \\
\hline $\mathrm{E}_{\mathrm{a}}$ & activation energy & $\xi^{*}$ & length fraction of the fine scales \\
\hline $\mathrm{h}$ & Enthalpy & $\mu_{\mathrm{i}}$ & eddy viscosity, Pa.s \\
\hline $\mathrm{J}_{\mathrm{j}}$ & diffusion flux of species $\mathrm{j}$ & $v$ & kinematic viscosity, $\mathrm{m}^{2} / \mathrm{s}$ \\
\hline $\mathrm{k}$ & Turbulence kinetic energy & $\rho$ & Density, $\mathrm{kg} / \mathrm{m} 3$ \\
\hline $\mathrm{N}$ & $\begin{array}{l}\text { total number of fluid phase } \\
\text { chemical species present in the } \\
\text { system }\end{array}$ & \multicolumn{2}{|c|}{ Abbreviations } \\
\hline $\mathrm{p}$ & pressure & & \\
\hline $\mathrm{R}$ & gas constant & CFD & computational fluid dynamics \\
\hline $\mathrm{r}$ & Radial direction & EDC & Eddy dissipation concept \\
\hline $\mathrm{R}_{\mathrm{i}}$ & $\begin{array}{l}\text { net rate of production of species i } \\
\text { by chemical reaction }\end{array}$ & DO & discrete ordinates \\
\hline $\mathrm{S}_{\mathrm{i}}$ & $\begin{array}{l}\text { rate of species production by } \\
\text { addition from the dispersed phase } \\
\text { plus any user-defined sources }\end{array}$ & GRI-Mech & detailed reaction mechanism \\
\hline $\mathrm{S}_{\mathrm{h}}$ & $\begin{array}{l}\text { heat of chemical reaction, and any } \\
\text { other volumetric heat sources }\end{array}$ & $\mathrm{JHC}$ & Jet-flame-in-hot-coflow \\
\hline $\mathrm{T}$ & Temperature, $\mathrm{K}$ & MILD & Moderate or intense low oxygen dilution \\
\hline$v_{x}$ & x-velocity & TMC & Traditional MILD combustion \\
\hline$v_{r}$ & Radial velocity & & \\
\hline
\end{tabular}




\section{Introduction}

Rapidly growing concerns about the emissions of greenhouse gases and the resultant climate change has significantly accelerated the development of renewable energy technologies [1-4]. Nonetheless, combustion of renewable and fossil fuels remains as an important method of energy generation for the foreseeable future. Recently, combustion of blends of green hydrogen and natural gas as a means of decarbonization of fuels has gained attention [5, 6]. Given the significance of combustion, many approaches are being explored to achieve high efficiency and reduced air pollutant emissions. MILD combustion is an advanced combustion technology with proven capabilities of delivering clean and efficient energy conversion [7, 8]. Yet, the physics of MILD combustion are still not fully understood and further research is required to unveil the complicated features of MILD combustion.

The fundamental aspects of MILD combustion of different types of fuels were presented by Weber et al. [5], with a focus on industrial applications. In recent years, many studies have been carried out to provide in-depth physical understanding on the dependency of MILD combustion upon various working conditions. For instance, Özdemir and Peters [9] examined the features of the MILD combustion reaction zones. They reported that when the equivalence ratio of the nonpremixed mixtures was increased, the reactive region was shifted away from the burner and extended further downstream towards the chamber ceiling. Wang et al. [10] conducted a numerical study and concluded that the effects of variations in preheat temperature are stronger than those of adding hydrogen. Ayoub et al. [11], Mendez et al. [12], Mardani and Tabejamaat [13], and Gao et al. [14] found that a zero emission furnace can be achieved through using pure $\mathrm{H}_{2}$ fuel without air preheating under MILD condition. Moreover, Wahid [15] and Yan et al. [16] reported that the uniform temperature distribution and more stable process inside the flameless chamber could be 
obtained by adding a small amount of $\mathrm{H}_{2}$. Mousavi et al. [17-19] explained that by injecting fuel with an angle into the combustion chamber, the net rates of reaction and entropy generation increase. Through investigation of MILD combustion in a turbine combustor, Deng et al. [20] found that the premixed combustion mode features more uniform reaction zone and lower peak temperature and pollutant emissions than those of non-premixed combustion. The dependency of oxy-MILD combustion regime on turbulent characteristics is numerically examined by Liu and An [8]. They found that the inlet nozzle spacing of combustor plays an important role on formation of oxy-MILD combustion. Li et al. [21] displayed that as the equivalence ratio increases, the NOreburning reaction becomes stronger. The study of Mardani and Ghomshi [22] showed that in comparison with the MILD condition the reaction rates are slower under Oxy-MILD. These authors, further, showed that Oxy-MILD combustion features lower Damköhler number with respect to the normal MILD. Dai et al. [23] found that both temperature and dimension of the jetin-hot-coflow flame reduce substantially when changing the diluent from $\mathrm{N}_{2}$ to $\mathrm{H}_{2} \mathrm{O}$. Sabia et al. [24] showed that an efficient recirculation of the exhausts produces a robust MILD combustion condition enabling combustion of low calorific fuels. Chinnici et al. [25] analyzed the thermal performance of a syngas-fuelled hybrid solar receiver combustor operated under MILD combustion regime. It was found that the type of fuel influences significantly the rate of radiative heat transfer and the ratio of radiative to convective heat transfer rates, and therefore the configuration must be optimized for each type of fuel. The same group [26] showed that MILD combustion can be successfully stabilized within the hybrid solar receiver combustor and it provides the ultra-low NO* and CO emissions. The pulverized coal Oxy-MILD combustion in $\mathrm{H}_{2} \mathrm{O} / \mathrm{CO}_{2}$ atmospheres was simulated by Zhang et al. [27]. It was found that the effects of gasification reactivity on flame temperature is weakened by $\mathrm{CO}_{2}$ replacement with $\mathrm{H}_{2} \mathrm{O}$. Tu et al. 
[28] showed that, due to chemical effects, $\mathrm{CO}_{2}$ dilution produces the lowest temperature increase under MILD combustion. Effects of Preheating and $\mathrm{CO}_{2}$ Dilution on Oxy-MILD combustion is numerically investigated by Moghadasi et al. [29]. They found that when diluting the oxidant, methylene $\mathrm{CH}_{2}$ (s) plays an important role in $\mathrm{CO}$ formation compared with when pure oxygen is used, contributing to higher $\mathrm{CO}$ emission.

Computational investigations on the physics of MILD combustion in different working conditions are often associated with major numerical challenges. Therefore, significant effort has been made to replicate the behavior of MILD combustion accurately and to produce pertinent and reliable numerical datasets. For instance, Christo and Dally [30] modeled turbulent MILD combustion and found that the eddy dissipation (EDC) model performs best in predicting the behavior of MILD combustion, and the same conclusion was made by Aminian et al. [31]. Hosseini and Galletti et al. [32] proposed two reduced NO formation models for CFD simulations of MILD combustion. Mardani [33] optimized the EDC model for simulation of MILD combustion of $\mathrm{CH}_{4}$ $\mathrm{H}_{2}$. Hu et al. [34] indicated the potential of transported PDF simulations with sensitivity analysis to investigate the effects of finite-rate chemistry on the flame characteristics and emissions and reveal the controlling physio-chemical processes in MILD combustion. Ferrarotti et al. [35] showed the major role of mixing models to correctly handle turbulence/chemistry interactions and clearly demonstrated the superior performances of dynamic mixing model over the other investigated approaches. Parente et al. [36] simulated MILD combustion using large eddy simulation methodology to study the effects of subgrid closure. Furthermore, the role of mixing models in the simulation of MILD combustion using finite-rate chemistry combustion models was investigated by Ferrarotti et al. [35]. 
It is well demonstrated that swirling flow burners have been advantageous to both premixed and non-premixed combustion systems because of their favorable influences on flame stability, combustion intensity and combustor performance [37-40]. It is therefore surprising that despite all the useful characteristics of swirl combustion, there is a shortage of in-depth studies of swirling MILD combustion. To address this issue, the current study investigates MILD combustion of a mixture of hydrogen and methane in a Jet-in-Hot Co-flow (JHC) burner by applying a swirling co-

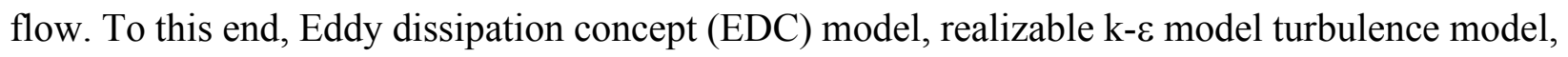
discrete ordinates radiation model [41, 42], and GRI 2.11 reaction mechanism are utilized.

\section{Governing Equations}

The simulated reactive flow is dominated by the continuity of mass, transport of momentum, energy, and species conservation. The equations are solved in the cylindrical coordinate and take the following format.

Continuity of mass: $\quad \frac{\partial \rho}{\partial t}+\frac{\partial}{\partial x}\left(\rho v_{x}\right)+\frac{\partial}{\partial r}\left(\rho v_{r}\right)+\frac{\rho v_{r}}{r}=0$

Transport of momentum $\quad \frac{\partial}{\partial t}\left(\rho v_{x}\right)+\frac{1}{r} \frac{\partial}{\partial x}\left(r \rho v_{x} v_{x}\right)+\frac{1}{r} \frac{\partial}{\partial r}\left(r \rho v_{r} v_{x}\right)=$ in axial direction:

$$
-\frac{\partial p}{\partial x}+\frac{1}{r} \frac{\partial}{\partial x}\left[r \mu\left(2 \frac{\partial v_{x}}{\partial x}-\frac{2}{3}(\nabla \cdot \vec{r})\right)\right]+\frac{1}{r} \frac{\partial}{\partial x}\left[r \mu\left(\frac{\partial v_{x}}{\partial r}+\frac{\partial v_{r}}{\partial x}\right)\right]
$$

Transport of momentum

$$
\frac{\partial}{\partial t}\left(\rho v_{r}\right)+\frac{1}{r} \frac{\partial}{\partial x}\left(r \rho v_{x} v_{r}\right)+\frac{1}{r} \frac{\partial}{\partial r}\left(r \rho v_{r} v_{r}\right)=
$$

in radial direction

$$
\begin{aligned}
& -\frac{\partial p}{\partial r}+\frac{1}{r} \frac{\partial}{\partial r}\left[r \mu\left(2 \frac{\partial v_{r}}{\partial r}-\frac{2}{3}\left(\nabla \cdot \frac{\mathrm{r}}{v}\right)\right)\right]+\frac{1}{r} \frac{\partial}{\partial x}\left[r \mu\left(\frac{\partial v_{x}}{\partial r}+\frac{\partial v_{r}}{\partial x}\right)\right] \\
& -2 \mu \frac{v_{r}}{r^{2}}+\frac{2}{3} \frac{\mu}{r}(\nabla \cdot v)+\rho \frac{v_{s}^{2}}{r}
\end{aligned}
$$

Transport of energy

$$
\frac{\partial}{\partial t}(\rho E)+\nabla \cdot(\stackrel{\mathrm{r}}{v}(\rho E+p))=-\nabla \cdot\left(\sum_{j} h_{j} J_{j}\right)+S_{h}
$$


Transport of chemical $\quad \frac{\partial}{\partial t}\left(\rho Y_{i}\right)+\nabla \cdot\left(\stackrel{\mathrm{r}}{\rho v} Y_{i}\right)=-\nabla \cdot \stackrel{\mathrm{r}}{J_{i}}+R_{i}+S_{i}$

species

In addition, the realizable k- $\varepsilon$ model is used to renormalize the Navier-Stokes equations to account for the effects of smaller scales of motion. Furthermore, the discrete ordinates model is applied to solve the radiative transfer equation and it is coupled with energy equation (Eq. (4)) based on Ref. [43].

\section{2-1. Eddy Dissipation Concept (EDC)}

Equation (5) is the conservation equation for chemical species in general form that solves for $\mathrm{N}-\mathrm{q}$ species. The net source of chemical species $I$ due to reaction, $R_{i}$ which appeared as the source term in the species transport equation is computed as the sum of the reaction sources over the $N_{R}$ reactions among the species.

The EDC is one of the turbulence-chemistry interaction models applicable to a wide range of combustion problems. In this method, the volume fraction of the fine scales and mean residence time $\left(\tau^{*}\right)$ are defined as

$$
\begin{aligned}
\xi^{*} & =\left(\frac{3 C_{D 2}}{4 C_{D 1}}\right)\left(\frac{v \varepsilon}{k^{2}}\right)^{3 / 4}=C_{\xi}\left(\frac{v \varepsilon}{k^{2}}\right)^{3 / 4} \\
\tau^{*} & =\left(\frac{C_{D 2}}{3}\right)^{1 / 2}\left(\frac{v}{\varepsilon}\right)^{1 / 2}=C_{\tau}\left(\frac{v}{\varepsilon}\right)^{1 / 2}
\end{aligned}
$$

In the present framework, the volume fraction constant $\left(C_{\xi}\right)$ and time scale constant $\left(C_{\tau}\right)$ are set to 3 and 1, respectively. The mean reaction rate in the conservation equation is shown in Eq. (8) which for the mean species $i$ is:

$$
R_{i}=\frac{\rho\left(\xi^{*}\right)^{2}}{\tau^{*}\left[1-\left(\xi^{*}\right)^{3}\right]}\left(Y_{i}^{*}-Y_{i}\right)
$$


The EDC model can incorporate detailed chemical mechanisms into turbulent reacting flows, while GRI. 2.11 reaction mechanism is used. In this mechanism, the reaction rate is calculated by the following relation,

$$
r=A T^{b} e^{-E_{a} / R T}
$$

Further, the variable of mixture fraction $(\mathrm{Z})$ parameter is used to study the flame structure in the $\mathrm{JHC}$ and it is calculated as follows [44]:

$$
Z=\frac{\frac{2\left(Y_{C}-Y_{C, 2}\right)}{W_{C}}+\frac{2\left(Y_{H}-Y_{H, 2}\right)}{2 W_{H}}-\frac{2\left(Y_{O}-Y_{O, 2}\right)}{W_{O}}}{\frac{2\left(Y_{C, 1}-Y_{C, 2}\right)}{W_{C}}+\frac{2\left(Y_{H, 1}-Y_{H, 2}\right)}{2 W_{H}}-\frac{2\left(Y_{O, 1}-Y_{O, 2}\right)}{W_{O}}}
$$

\section{Configuration, computational grid and Boundary Condition}

The current work includes two parts. In the first part, the numerical results are compared with the experimental data [45] obtained from a configuration in which the hot co-flow is injected to the burner axially. In the following step, the behavior of MILD combustion is investigated using swirl hot coflow conditions. Figure 1a shows a schematic view of the laboratory-scale burner of Dally $[30,45]$. In Dally's burner the flows inject to the burner axially. This is a co-flow burner and includes a wind tunnel, hot coflow inlet and fuel inlet with diameters of 210,80 , and $4.25 \mathrm{~mm}$, respectively. The wind tunnel air consists of $23 \% \mathrm{O}_{2}$ and $77 \% \mathrm{~N}_{2}$ with the velocity of $3.2 \mathrm{~m} / \mathrm{s}$. The temperature of wind tunnel is maintained at $300 \mathrm{~K}$ while the hot coflow preheats up to $1300 \mathrm{~K}$. $\mathrm{N}_{2}, \mathrm{H}_{2} \mathrm{O}, \mathrm{CO}_{2}$, and $\mathrm{O}_{2}$ are the components of hot coflow with the velocity of $3.2 \mathrm{~m} / \mathrm{s}$ in the case of TMC. According to Fig. 1b, in the second part of the current work, the hot coflow is injected under swirl configuration and for these cases the details are shown in table 1. Further, the inlet fuel injected at the center of the burner consists of $\mathrm{H}_{2}-\mathrm{CH}_{4}(11.1 \%, 88.9 \%)$ with the inlet Reynolds number of 10000 . The inlet conditions for the present study are summarized in table 1. 
The upstream boundary conditions are set by velocity profiles, inlet temperature and species mass fractions. The results of the present work illustrate that the solution is not sensitive to turbulence intensity at the hot co-flow and wind tunnel inlets. This finding is consistent with that reported by Christo et al. [30] and Frassoldati et al. [46]. However, the turbulence intensity at the fuel inlet is important. Ref. [45] did not report the experimental data relating to turbulence, while Christo et al. [30] reported the experimentally estimated mean turbulent kinetic energy of $16 \mathrm{~m}^{2} / \mathrm{s}^{2}$ (it is approximately equivalent to $4 \%$ ) at the fuel inlet, although it was adjusted to $60 \mathrm{~m}^{2} / \mathrm{s}^{2}$ in their modeling (it approximately is equivalent to $7.5 \%$ ). In the present study, the fuel turbulence intensity was adjusted to be $7 \%$ to yield the best agreement between the calculated and measured mixture fraction distribution. In addition, Fig. 2 shows the sample of cells configuration of the investigated configuration, which was obtained after conduction of an extensive grid independency study, and it consists of 45000 structured cells.

\section{Validation}

In this section, the results from the finite volume solver are compared with the experimental data reported in Ref. [45] to validate the numerical framework. A comparison between the predicted mixture fraction and the experimental data at three radial locations of 30,60 , and $120 \mathrm{~mm}$ is shown in Fig. 3. Evidently, there is a good agreement between the mixture fractions at all positions obtained from the current finite volume code and those obtained experimentally; confirming that the present numerical setting is capable of predicting MILD combustion behaviors under various working conditions.

\section{Results and discussion}

In this section, the effects of swirl inlet velocity of hot coflow on the characteristics of MILD combustion are investigated. The boundary condition and the inlet properties are the same as section 3, and the inlet swirl velocities of hot coflow are those of table 2. Contours of Fig. 4 
represent the temperature distribution for traditional MILD combustion (TMC), S0.8 to S9.6. Comparing the swirl (S0.8-S9.6) and TMC conditions, it is clear that the temperature field has changed significantly by switching to the swirl flow conditions. For TMC case the hot coflow completely surrounds the high temperature gases produced by MILD combustion. These gases are produced downstream of the fuel injection nozzle and form a relatively narrow hot region. Addition of swirl results in elimination of the surrounding hot flow and yet widens the width of the area occupied with hot gases. Importantly, the sudden changes in the temperature of the reacting flow occurs in a region closer to the inlet fuel nozzle. It will be later shown that this is due to an upstream shift of combustion reactions. This means that by using swirl co-flow, the delay in combustion has diminished and thus the reactive flow residence time has increased.

It should be noted that addition of swirl flow increases the turbulence intensity. This enhances the impacts of hot co-flow upon the reactants and results in more complete combustion. Therefore, the heat of reaction increases and consequently the flow temperature rises. By comparing the considered swirl cases (S0.8 to S9.6) in Fig. 4, it is apparent that the thickness of the hightemperature zone is higher in the inlet area. This is due to the higher mass flow rate of the preheated inlet flow at higher swirl velocities. Nevertheless, according to Fig. 5, the flow temperature at the reacting zone centerline are higher for all the swirl cases than the corresponding points in TMC. By comparing the swirl cases in Fig. 5, it is evident that at higher swirl velocity the temperature increases faster along the burner centerline, implying a faster heat release. Further, considering the temperature distribution in the radial direction for different axial locations in Fig. 6, it is clear that the maximum flow temperature increases when swirl flow is established. Once again, this is indicative of faster heat release in swirling cases. A notable point in Fig. 6 is the axial distance of $0.025 \mathrm{~m}$, where combustion has not occurred for the TMC, and the temperature is still equal to the 
temperature of the preheated flow. However, at the same axial location and for the swirl cases, the maximum temperature exceeds $2000 \mathrm{~K}$ indicating intense reactions. Fig. 6 further shows that the ignition delay decreases dramatically when swirl conditions are applied. Also, by comparing the swirl cases, it is found that the maximum temperature is almost similar for different cases. Nonetheless, at larger radial distances, the combustion temperature for the S0.96 case is larger, which is due to the presence of more oxygen in those regions. Farther downstream of the inlet nozzle and at the distances of 0.15 and $0.2 \mathrm{~m}$, the temperature distribution includes less variations in comparison with that in locations closer to the nozzle outlet.

Figure 7 shows the radial distribution of mass fraction of $\mathrm{OH}$ free radicals at different axial locations. This chemical species is one of the main parameters used to determine the behavior of reacting flows as the reaction zone can be identified by the presence of this species. Considering the trend of changes of $\mathrm{OH}$ in Fig. 7, it is clear that by applying the swirl flow conditions, the amount of this radical increases substantially up to about 10 times. In keeping with the earlier discussions, this confirm that in the swirling cases the energy released at the investigated axial locations has increased. It should also be mentioned that according to Fig. 7, the width of reactive region increases significantly when swirl flow is in place. For instance, this figure shows that at an axial distance of $0.01 \mathrm{~m}$, the width of reactive region has increased by about $25 \%$ and therefore, the generated reactive flow has radially expanded. A similar trend is observed at other axial locations.

The contours in Fig. 8 show the distribution of the mass fraction of $\mathrm{OH}$ radical for different cases presented in table 2. According to these contours, the spatial variation of $\mathrm{OH}$ radical is significantly different for swirl and TMC cases, such that swirl flow causes the location of the sharp gradient of $\mathrm{OH}$ to approach closer to the inlet nozzle. The starting point of this gradient is 
shown in Fig 9, which demonstrates that by using swirl flow, the location of combustion initiation is pushed very close to the inlet nozzle. Figure 8 clearly shows that this trend is further augmented by increasing the swirl velocity. This could be attributed to the increased turbulence intensity, which intensifies the combustion process and therefore pushes the reactive region towards upstream. Further, when comparing the swirl case S0.8 to S9.6 in Fig. 7, it is observed that by increasing the swirl velocity up to the distance of $0.15 \mathrm{~m}$ from the inlet, the reactive region generated in case of S9.6 is thicker. However, by moving away from this region, the thickness of reactive part of the flow is no longer dependent on the swirl conditions.

The graphs in Fig. 10 show the distribution of the mass fraction of HCO (formyl radical) at different axial distances along the burner radius. According to this figure, the distribution of formyl radical, representing the heat release during the combustion [47], is highly dependent on the hot co-flow entering the reactive region. Considering this figure, it is evident that the amount of HCO at distances near the inlet is significantly lower in the TMC than that of the swirl cases. For TMC combustion takes place away from the inlet nozzle and therefore, in comparison with the swirling cases, heat is released at a longer distance from the fuel inlet nozzle. Further, as S0.8 to S3.2 cases show, the amount of formyl at an axial distance of $0.025 \mathrm{~m}$ is higher than the corresponding amounts at S6.4 and S9.6 cases. This is because the location of combustion initiation is very close to the inlet for these cases, and an intense heat release occurs between the inlet nozzle and a downstream distance of $0.025 \mathrm{~m}$. For the cases of S0.8 to S3.2, considering the location of combustion initiation, a high value of $\mathrm{HCO}$ is expected at the axial distance of $0.025 \mathrm{~m}$. Further, it can be observed in Fig. 10 that by gradually moving away from the inlet, the total amount of formyl radical decreases for various cases as it is far from the initial reaction zone. In other words, the farther axial locations shown in Fig. 10 are away from the initial stages of fuel decomposition. 
Although in regions away from the inlet, the HCO produced in TMC condition increases, the average amount of this radical is higher for the swirl cases than the TMC.

The spatial variations of $\mathrm{HCO}$ free radical are depicted in Fig. 11. It can be observed that by changing the hot co-flow inlet conditions from TMC to various swirl states, the location of the maximum HCO free radical has changed in accordance with the alteration of the initial ignition location. By referring to the contours of S6.4 and S9.6, it is clear that the maximum of formyl concentration occurs in the vicinity of the fuel inlet nozzle. This is consistent with the earlier results indicating that addition of swirl pushes the reactive region upstream and towards the inlet fuel nozzle. Figure 12 shows the contours of $\mathrm{CH}_{2} \mathrm{O}$ species (formaldehyde) generated by the combustion of $\mathrm{CH}_{4}-\mathrm{H}_{2}$ through breaking the molecular bonds of $\mathrm{H}_{2}$ [48]. This is indicative of the accelerated speed of fuel decomposition, while it also illustrates increases in the level of heat release [48]. It is clear in Fig. 12 that by applying swirl conditions, the radial distribution of $\mathrm{CH}_{2} \mathrm{O}$ has become more uniform and strong gradients of formaldehyde do not exist anymore. This behavior re-confirms that by applying swirl conditions the reaction zone has expanded significantly and that the reactions are now taking place in larger volume. The presence of $\mathrm{CH}_{2} \mathrm{O}$ species in the fuel rich zone (especially for S6.4 and S9.6) shows that this chemical species is produced in the initial stages of fuel decomposition. Therefore, the delay in combustion has been reduced significantly.

Considering the molar ratio of $\mathrm{CH}_{4}$ and $\mathrm{H}_{2}$ in the fuel inlet nozzle in accordance with table 2, it is clear that the primary fuel is $\mathrm{CH}_{4}$. Further, due to the very high reactivity of hydrogen, it is anticipated that hydrogen combustion occurs much quicker than that of methane. Therefore, in this section, the axial variations in the concentration of this molecule is investigated. Figure 13 represents the molar concentration of $\mathrm{CH}_{4}$ along the burner centerline up to the outlet wherein 
methane concentration has dropped to zero. As can be observed in this figure, by establishing swirl conditions at similar points, the amount of unburned $\mathrm{CH}_{4}$ for $\mathrm{TMC}$ is considerably higher than that for the swirl cases (up to about $30 \%$ ). This is due to the existence of reburning with applying the swirl condition [49]. According to the earlier discussions with regard to the reduction of ignition delay when using swirl condition, it can be stated that the amount of resistance time increases using the swirl condition and it provides sufficient time for the chemical reactions to fully take place. Towards the burner outlet, it is clear that the amount of unburned $\mathrm{CH}_{4}$ of $\mathrm{TMC}$ is more than the cases of S0.8 to S9.6 and by comparing the swirl cases. This is to be expected as by reducing the swirl velocity, the amount of unburned $\mathrm{CH}_{4}$ has diminished due to the increased residence time of reacting flow. Hence, the presented results imply that addition of swirl leads to shortening of the reactive region and completion of heat release in a more compact area.

Figure 14 shows the radial distribution of the $\mathrm{HO}_{2}$ (hydroperoxyl) radical. This radical denotes the recombination process in the reacting flow $[50,51]$ and it is known as a key species in the occurrence of ignition [52]. The production of this radical is depending on the generation of $\mathrm{CH}_{2} \mathrm{O}$, $\mathrm{O}_{2}, \mathrm{H}_{2} \mathrm{O}, \mathrm{N}_{2}, \mathrm{OH}$, and $\mathrm{HCO}$ through table 3. Given the preceding discussions, the amount of $\mathrm{OH}$ and $\mathrm{CH}_{2} \mathrm{O}$ increases by applying the swirl condition. In addition, increasing the swirl velocity causes $\mathrm{N}_{2}, \mathrm{O}_{2}$, and $\mathrm{H}_{2} \mathrm{O}$ mass fractions to increase. Based on variations in $\mathrm{OH}$ and $\mathrm{HCO}$ radicals in Figs. 7 and 10 and according to Fig. 14, for the close distances from the inlet nozzle and on the burner centerline, the concentration of $\mathrm{HO}_{2}$ species is higher for the TMC than the swirl combustion. However, by travelling farther downstream and moving crosswise in the burner, the amount of hydroperoxyl radical is observed to be higher for the swirl flows. Also, by considering the variations of $\mathrm{HO}_{2}$ radical at different axial locations, it is clear that by moving away from the inlet nozzles, the amount of $\mathrm{HO}_{2}$ for $\mathrm{TMC}$ decreases, while it increases significantly for the swirl 
combustion. Furthermore, by travelling downstream of the inlet nozzles, the concentration of $\mathrm{HO}_{2}$ reduces for the TMC and increases for the $\mathrm{S} 0.8$ to $\mathrm{S} 9.6$ cases. Therefore, the mass fraction of $\mathrm{HO}_{2}$ free radical increases with applying the swirl condition. These involved behaviors of hydroperoxyl radical have direct consequences upon the $\mathrm{NO}_{\mathrm{x}}$ emissions of the burner. It has been shown that hydroperoxyl correlates strongly with production of prompt NO in hydrocarbon fuel combustion [49]. Hence, according to Fig. 15, the rate of prompt NO increases with applying the swirl MILD combustion and this rate grows with the growth in swirl velocity. In addition, due to the increased combustion temperature, and with regard to the direct relation between thermal $\mathrm{NO}$ emissions and temperature the use of swirl flow leads to an increase in thermal NO emission. This is depicted by Fig. 16 which shows the average mass fraction of $\mathrm{NO}$ emission at the outlet zone of the burner. Clearly, using swirl condition causes the amount of NO to increase rather significantly. As a remedy, the temperature of hot co-flow can be reduced to avoid high temperatures in the reactive flow and suppress the mechanism of thermal $\mathrm{NO}_{\mathrm{x}}$. Through doing this, the Mild conditions are retained, the cost of flow preheating is decreased, and the $\mathrm{NO}$ emissions are reduced.

As observed in the Figs. 10 and 11, the average production of HCO for the TMC is slightly higher than S0.8 to S9.6 cases. One of the effective parameters on $\mathrm{CO}$ generation is the presence of $\mathrm{HCO}$ radical [53], its reduction under the swirl condition leads to drop of the produced $\mathrm{CO}$. Further, increase in combustion temperature decreases the amount of $\mathrm{CO}$ and unburned hydrocarbon emissions by preventing the quenching of oxidation reactions [49]. Consequently, as shown in Fig. 17, using swirl flow for hot co-flow causes CO production to decrease at the outlet of the burner [56,57]. 


\section{Conclusions}

The effects of adding swirling hot co-flow upon combustion of a mixture of hydrogen and methane in a burner operating under MILD regime was investigated numerically. The governing equations were solved using a finite volume, Reynold Averaged Navier-Stokes (RANS) solver in an axisymmetric configuration and with the inclusion of GRI. 2.11 reaction mechanism and the discrete ordinates model of thermal radiation. A non-swirling base case and five test cases with different swirl velocities were simulated. The numerical results were carefully validated against the existing experimental data. The key outcome of this work can be summarized as follows.

- Analyses of the temperature fields as well as those of $\mathrm{OH}$ and $\mathrm{HCO}$ radicals showed that addition of swirl to the MILD combustion burner reduces the ignition delay and therefore pushes the exothermic reactions towards the outlet of the fuel nozzle.

- Spatial distributions of temperature, formaldehyde and hydroperoxyl showed that application of swirling hot co-flow leads to radial expansion of the reactive flow.

- It was demonstrated that addition of swirl reduces the length of the reactive flow and thus allows for achieving full heat release in a shorter axial distance.

- Modification of formyl radical and flow temperature by swirl co-flow leads to suppression of $\mathrm{CO}$ emissions.

- Increases in the concentration of hydroperoxyl radical and flow temperature increase the emission of $\mathrm{NO}_{\mathrm{x}}$ in all investigated swirling cases in comparison with the non-swirling base case.

This study revealed the advantages of applying swirl co-flow to MILD combustion burners. The issue of increased $\mathrm{NO}_{\mathrm{x}}$ emission is expected to be largely resolved by reducing the temperature of 
recycled flue gas in practical burners. Nonetheless, this remains as an important problem for consideration in future studies.

\section{References}

[1] Sotoudeh, F., Kamali, R., and Mousavi, S. M., 2019, "Field tests and numerical modeling of INVELOX wind turbine application in low wind speed region," Energy, 181, pp. 745-759.

[2] Dean, J., Braun, R., Penev, M., Kinchin, C., and Muñoz, D., 2011, "Leveling Intermittent Renewable Energy Production Through Biomass Gasification-Based Hybrid Systems," Journal of Energy Resources Technology, 133(3).

[3] Fattahi, A., Hosseinalipour, S. M., Karimi, N., Saboohi, Z, Ommi F., 2019 "On the response of the exit nozzle of a lean-premixed hydrogen combustor to acoustic and dissipative-dispersive entropy waves" Energy, 180, 272-291,

[4] Khojasteh, D., Mousavi, S. M., Glamore, W., and Iglesias, G., 2018, "Wave energy status in Asia," Ocean Engineering, 169, pp. 344-358.

[5] Sanusi, Y. S., Mokheimer, E. M. A., Shakeel, M. R., Abubakar, Z., and Habib, M. A., 2017, "Oxy-Combustion of Hydrogen-Enriched Methane: Experimental Measurements and Analysis," Energy \& Fuels, 31(2), pp. 2007-2016.

[6] Di Iorio, S., Sementa, P., and Vaglieco, B. M., 2016, "Analysis of combustion of methane and hydrogen-methane blends in small DI SI (direct injection spark ignition) engine using advanced diagnostics," Energy, 108, pp. 99-107.

[7] Cavaliere, A., and de Joannon, M., 2004, "Mild Combustion," Progress in Energy and Combustion Science, 30(4), pp. 329-366.

[8] Liu, R., and An, E., 2017, "Turbulent Flame Characteristics of Oxycoal MILD Combustion," Journal of Energy Resources Technology, 139(6), p. 062206. 
[9] Özdemir, İ. B., and Peters, N., 2001, "Characteristics of the reaction zone in a combustor operating at mild combustion," Experiments in Fluids, 30(6), pp. 683-695.

[10] Wang, F., Mi, J., Li, P., and Zheng, C., 2011, "Diffusion flame of a $\mathrm{CH}_{4} / \mathrm{H}_{2}$ jet in hot lowoxygen coflow," International Journal of Hydrogen Energy, 36(15), pp. 9267-9277.

[11] Ayoub, M., Rottier, C., Carpentier, S., Villermaux, C., Boukhalfa, A. M., and Honoré, D., 2012, "An experimental study of MILD flameless combustion of methane/hydrogen mixtures," International Journal of Hydrogen Energy, 37(8), pp. 6912-6921.

[12] Arteaga Mendez, L. D., Tummers, M. J., van Veen, E. H., and Roekaerts, D. J. E. M., 2015, "Effect of hydrogen addition on the structure of natural-gas jet-in-hot-coflow flames," Proceedings of the Combustion Institute, 35(3), pp. 3557-3564.

[13] Mardani, A., and Tabejamaat, S., 2010, "Effect of hydrogen on hydrogen-methane turbulent non-premixed flame under MILD condition," International Journal of Hydrogen Energy, 35(20), pp. 11324-11331.

[14] Gao, X., Duan, F., Lim, S. C., and Yip, M. S., 2013, "NO formation in hydrogen-methane turbulent diffusion flame under the moderate or intense low-oxygen dilution conditions," Energy, 59, pp. 559-569.

[15] Hosseini, S. E., and Wahid, M. A., 2014, "Development of biogas combustion in combined heat and power generation," Renewable and Sustainable Energy Reviews, 40, pp. 868-875.

[16] Yan, Y., Tang, W., Zhang, L., Pan, W., Yang, Z., Chen, Y., and Lin, J., 2014, "Numerical simulation of the effect of hydrogen addition fraction on catalytic micro-combustion characteristics of methane-air," International Journal of Hydrogen Energy, 39(4), pp. 1864-1873. 
[17] Mousavi, S. M., Abolfazli-Esfahani, J., and Yazdi-Mamaghani, M., 2014, "Numerical study of entropy generation in the flameless oxidation using large eddy simulation model and OpenFOAM software," International Journal of Thermodynamics, 17(4), pp. 202-208.

[18] Mousavi, S. M., and Abolfazli-Esfahani, J., 2014, "Numerical Investigation of the Flameless Oxidation of Natural Gas in the IFRF Furnace Using Large Eddy Simulation," International Journal of Spray and Combustion Dynamics, 6(4), pp. 387-410.

[19] Kamali, R., Mousavi, S. M., Binesh, A. R., and Abolfazli-Esfahani, J., 2016, "Large eddy simulation of the flameless oxidation in the IFRF furnace with varying inlet conditions," International Journal of Spray and Combustion Dynamics, 9(2), pp. 102-115.

[20] Deng, X., Xiong, Y., Yin, H., and Gao, Q., 2016, "Numerical study of the effect of nozzle configurations on characteristics of MILD combustion for gas turbine application," Journal of Energy Resources Technology, 138(4), p. 042212.

[21] Li, P., Wang, F., Mi, J., Dally, B. B., Mei, Z., Zhang, J., and Parente, A., 2014, "Mechanisms of NO formation in MILD combustion of $\mathrm{CH}_{4} / \mathrm{H}_{2}$ fuel blends," International Journal of Hydrogen Energy, 39(33), pp. 19187-19203.

[22] Mardani, A., and Fazlollahi Ghomshi, A., 2016, "Numerical study of oxy-fuel MILD (moderate or intense low-oxygen dilution combustion) combustion for $\mathrm{CH}_{4}-\mathrm{H}_{2}$ fuel," Energy, 99 , pp. $136-151$.

[23] Dai, C., Shu, Z., Li, P., and Mi, J., 2018, "Combustion characteristics of a methane jet flame in hot oxidant coflow diluted by $\mathrm{H}_{2} \mathrm{O}$ versus the case by $\mathrm{N}_{2}$," Energy \& Fuels, 32(1), pp. $875-888$. 
[24] Sabia, P., Sorrentino, G., Bozza, P., Ceriello, G., Ragucci, R., and de Joannon, M., 2019, "Fuel and thermal load flexibility of a MILD burner," Proceedings of the Combustion Institute, 37(4), pp. 4547-4554.

[25] Chinnici, A., Tian, Z. F., Lim, J. H., Nathan, G. J., and Dally, B. B., 2019, "Thermal performance analysis of a syngas-fuelled hybrid solar receiver combustor operated in the MILD combustion regime," Combustion Science and Technology, 191(1), pp. 2-17.

[26] Chinnici, A., Nathan, G. J., and Dally, B. B., 2019, "An experimental study of the stability and performance characteristics of a Hybrid Solar Receiver Combustor operated in the MILD combustion regime," Proceedings of the Combustion Institute, 37(4), pp. 5687-5695.

[27] Zhang, Z., Li, X., Zhang, L., Luo, C., Lu, B., Xu, Y., Liu, J., Chen, A., and Zheng, C., 2019, "Effect of H2O/CO2 mixture on heat transfer characteristics of pulverized coal MILD-oxy combustion," Fuel Processing Technology, 184, pp. 27-35.

[28] Tu, Y., Xu, M., Zhou, D., Wang, Q., Yang, W., and Liu, H., 2019, "CFD and kinetic modelling study of methane MILD combustion in $\mathrm{O}_{2} / \mathrm{N}_{2}, \mathrm{O}_{2} / \mathrm{CO}_{2}$ and $\mathrm{O}_{2} / \mathrm{H}_{2} \mathrm{O}$ atmospheres," Applied Energy, 240, pp. 1003-1013.

[29] Moghadasi, M. H., Riazi, R., Tabejamaat, S., and Mardani, A., 2019, "Effects of preheating and $\mathrm{CO}_{2}$ dilution on oxy-MILD combustion of natural gas," Journal of Energy Resources Technology, 141(12), p. 122002.

[30] Christo, F. C., and Dally, B. B., 2005, "Modeling turbulent reacting jets issuing into a hot and diluted coflow," Combustion and Flame, 142(1), pp. 117-129.

[31] Aminian, J., Galletti, C., Shahhosseini, S., and Tognotti, L., 2012, "Numerical investigation of a MILD combustion burner: analysis of mixing field, chemical kinetics and turbulencechemistry interaction," Flow, Turbulence and Combustion, 88(4), pp. 597-623. 
[32] Galletti, C., Ferrarotti, M., Parente, A., and Tognotti, L., 2015, "Reduced NO formation models for CFD simulations of MILD combustion," International Journal of Hydrogen Energy, 40(14), pp. 4884-4897.

[33] Mardani, A., 2017, "Optimization of the Eddy Dissipation Concept (EDC) model for turbulence-chemistry interactions under hot diluted combustion of $\mathrm{CH} 4 / \mathrm{H} 2$," Fuel, 191, pp. 114129.

[34] Wang, H., Zhou, H., Ren, Z., and Law, C. K., 2019, "Transported PDF simulation of turbulent $\mathrm{CH}_{4} / \mathrm{H}_{2}$ flames under MILD conditions with particle-level sensitivity analysis," Proceedings of the Combustion Institute, 37(4), pp. 4487-4495.

[35] Ferrarotti, M., Li, Z., and Parente, A., 2019, "On the role of mixing models in the simulation of MILD combustion using finite-rate chemistry combustion models," Proceedings of the Combustion Institute, 37(4), pp. 4531-4538.

[36] Li, Z., Cuoci, A., and Parente, A., 2019, "Large Eddy Simulation of MILD combustion using finite rate chemistry: Effect of combustion sub-grid closure," Proceedings of the Combustion Institute, 37(4), pp. 4519-4529.

[37] Christodoulou L., Karimi N., Cammarano A., Paul M., Navarro-Martinez S., 2020 "State prediction of an entropy wave advecting through a turbulent channel flow", Journal of Fluid Mechanics, 882, A8.

[38] Karimi, N., McGrath, S., Brown, P., Weinkauff, J., and Dreizler, A., 2016, "Generation of Adverse Pressure Gradient in the Circumferential Flashback of a Premixed Flame," Flow, Turbulence and Combustion, 97(2), pp. 663-687. 
[39] Christodoulou, L., Kabiraj, L., Saurabh, A., and Karimi, N., 2016, "Characterizing the signature of flame flashback precursor through recurrence analysis," Chaos: An Interdisciplinary Journal of Nonlinear Science, 26(1), p. 013110.

[40] Kabiraj, L., Saurabh, A., Karimi, N., Sailor, A., Mastorakos, E., Dowling, A. P., and Paschereit, C. O., 2015, "Chaos in an imperfectly premixed model combustor," Chaos: An Interdisciplinary Journal of Nonlinear Science, 25(2), p. 023101.

[41] Chui, E. H., and Raithby, G. D., 1993, "Computation of radiant heat transfer on a nonorthogonal mesh using the finite-volume method," Numerical Heat Transfer, Part B: Fundamentals, 23(3), pp. 269-288.

[42] Wang, L., Karimi, N., Sutardi, T., Paul, M., 2019 “Combustion characteristics and pollutant emissions in transient oxy-combustion of a single biomass particle-A numerical study", Energy \& Fuels, 33, 2, 1556-1569

[43] Mathur, S. R., and Murthy, J. Y., 1999, "Coupled ordinates method for multigrid acceleration of radiation calculations," Journal of Thermophysics and Heat Transfer, 13(4), pp. 467-473.

[44] Bilger, R. W., Stårner, S. H., and Kee, R. J., 1990, "On reduced mechanisms for methaneair combustion in nonpremixed flames," Combustion and Flame, 80(2), pp. 135-149.

[45] Dally, B. B., Karpetis, A. N., and Barlow, R. S., 2002, "Structure of turbulent non-premixed jet flames in a diluted hot coflow," Proceedings of the Combustion Institute, 29(1), pp. 1147-1154. [46] Frassoldati, A., Sharma, P., Cuoci, A., Faravelli, T., and Ranzi, E., 2010, "Kinetic and fluid dynamics modeling of methane/hydrogen jet flames in diluted coflow," Applied Thermal Engineering, 30(4), pp. 376-383. 
[47] Nikolaou, Z. M., and Swaminathan, N., 2014, "Heat release rate markers for premixed combustion," Combustion and Flame, 161(12), pp. 3073-3084.

[48] Mansourian, M., Kamali, R., and Jeung, I.-S., 2019, "Numerical investigation of embedding some hot obstacles in a low speed reacting flow of the moderate or intense low-oxygen dilution in a jet-in-hot-coflow," Acta Astronautica, 162, pp. 536-545.

[49] El-Mahallawy, F., and Habik, S.-D., 2002, Fundamentals and technology of combustion, Elsevier.

[50] Asadi, A., Kadijani, O. N., Doranehgard, M. H., Bozorg, M. V., Xiong, Q., Shadloo, M.

S., Li, L. K., 2019. Numerical study on the application of biodiesel and bioethanol in a multiple injection diesel engine. Renewable Energy. https://doi.org/10.1016/j.renene.2019.11.088

[51] Hong, Z., Vasu, S. S., Davidson, D. F., and Hanson, R. K., 2010, "Experimental study of the rate of $\mathrm{OH}+\mathrm{HO}_{2} \rightarrow \mathrm{H}_{2} \mathrm{O}+\mathrm{O}_{2}$ at high temperatures using the reverse reaction," The Journal of Physical Chemistry A, 114(17), pp. 5520-5525.

[52] Blocquet, M., Schoemaecker, C., Amedro, D., Herbinet, O., Battin-Leclerc, F., and Fittschen, C., 2013, "Quantification of $\mathrm{OH}$ and $\mathrm{HO}_{2}$ radicals during the low-temperature oxidation of hydrocarbons by Fluorescence Assay by Gas Expansion technique," Proceedings of the National Academy of Sciences, 110(50), p. 20014.

[53] Stoecklin, T., Halvick, P., Yu, H.-G., Nyman, G., and Ellinger, Y., 2018, "On the gas-phase formation of the $\mathrm{HCO}$ radical: accurate quantum study of the $\mathrm{H}+\mathrm{CO}$ radiative association," Monthly Notices of the Royal Astronomical Society, 475(2), pp. 2545-2552.

[54] Bowman, C., Hanson, R., Gardiner, W., Lissianski, V., Frenklach, M., Goldenberg, M., and Smith, G., 1997, "GRI-Mech 2. 11: an optimized detailed chemical reaction mechanism for methane combustion and NO formation and reburning," NASA(19980005146). 
[55] Bozorg, M. V., Doranehgard, M. H., Hong, K., Xiong, Q., Li, L. K. 2019. A numerical study on discrete combustion of polydisperse magnesium aero-suspensions. Energy, 194, 116872.

[56] Saffarian, M. R., Bahoosh, R., Doranehgard, M. H., 2019. Entropy generation in the intake pipe of an internal combustion engine. The European Physical Journal Plus, 134(9), 476.

[57] Athar, K., Doranehgard, M. H., Eghbali, S., Dehghanpour, H., 2019. Measuring diffusion coefficients of gaseous propane in heavy oil at elevated temperatures. Journal of Thermal Analysis and Calorimetry, 1-13. 


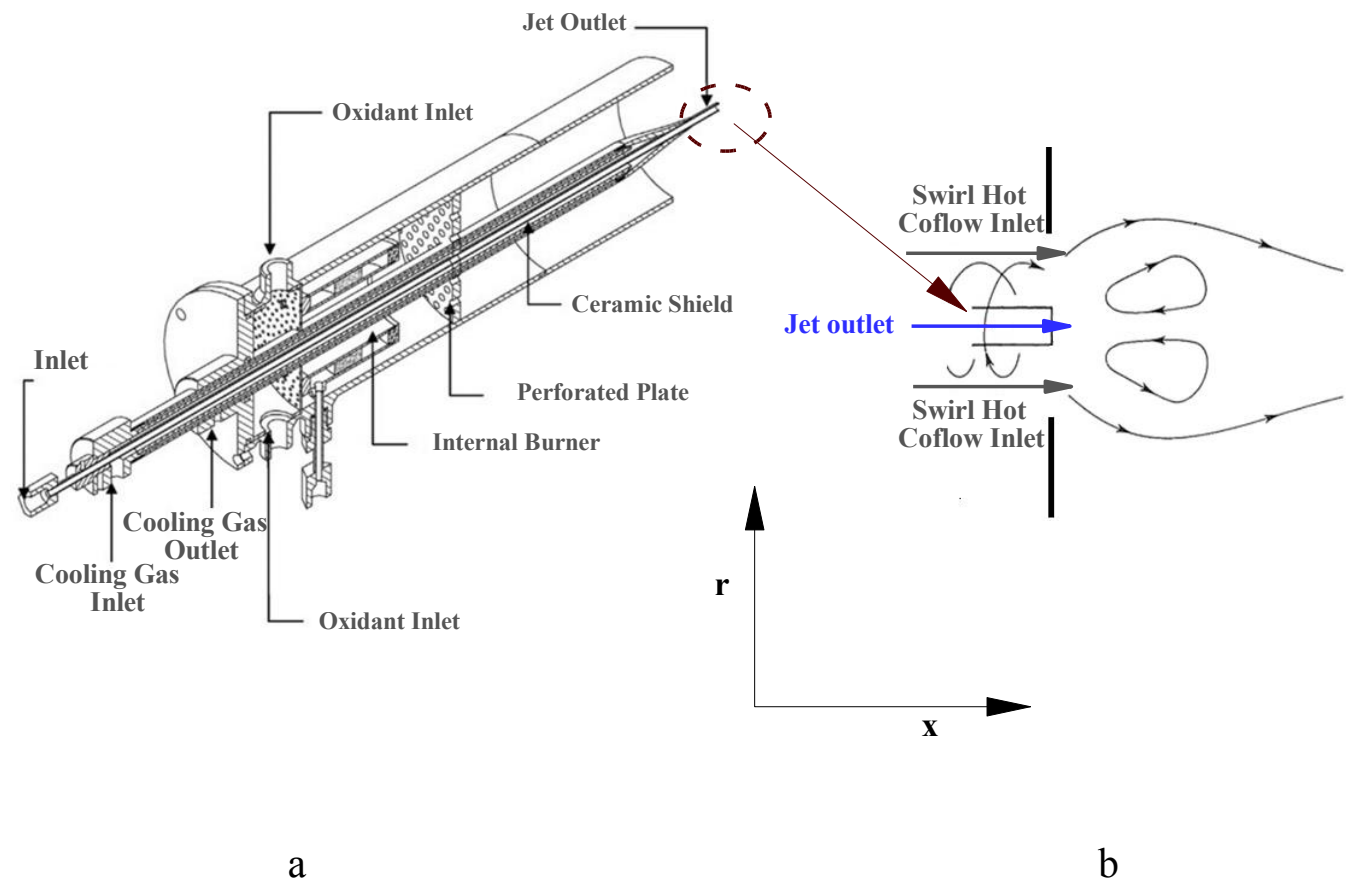

Figure 1. Schematic of the investigated burner [30, 45]. 


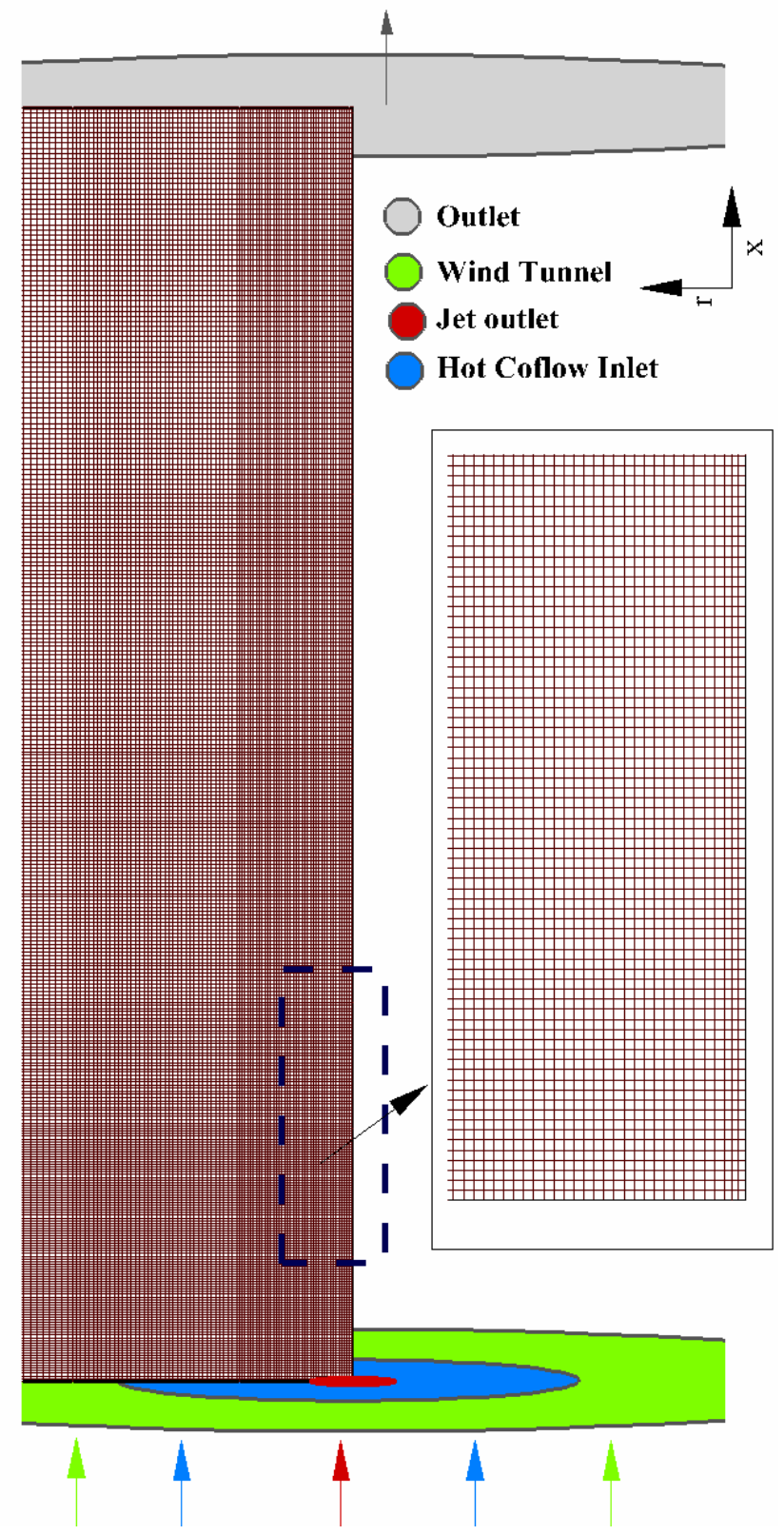

Figure 2. Sample grid configuration of the computational domain. 


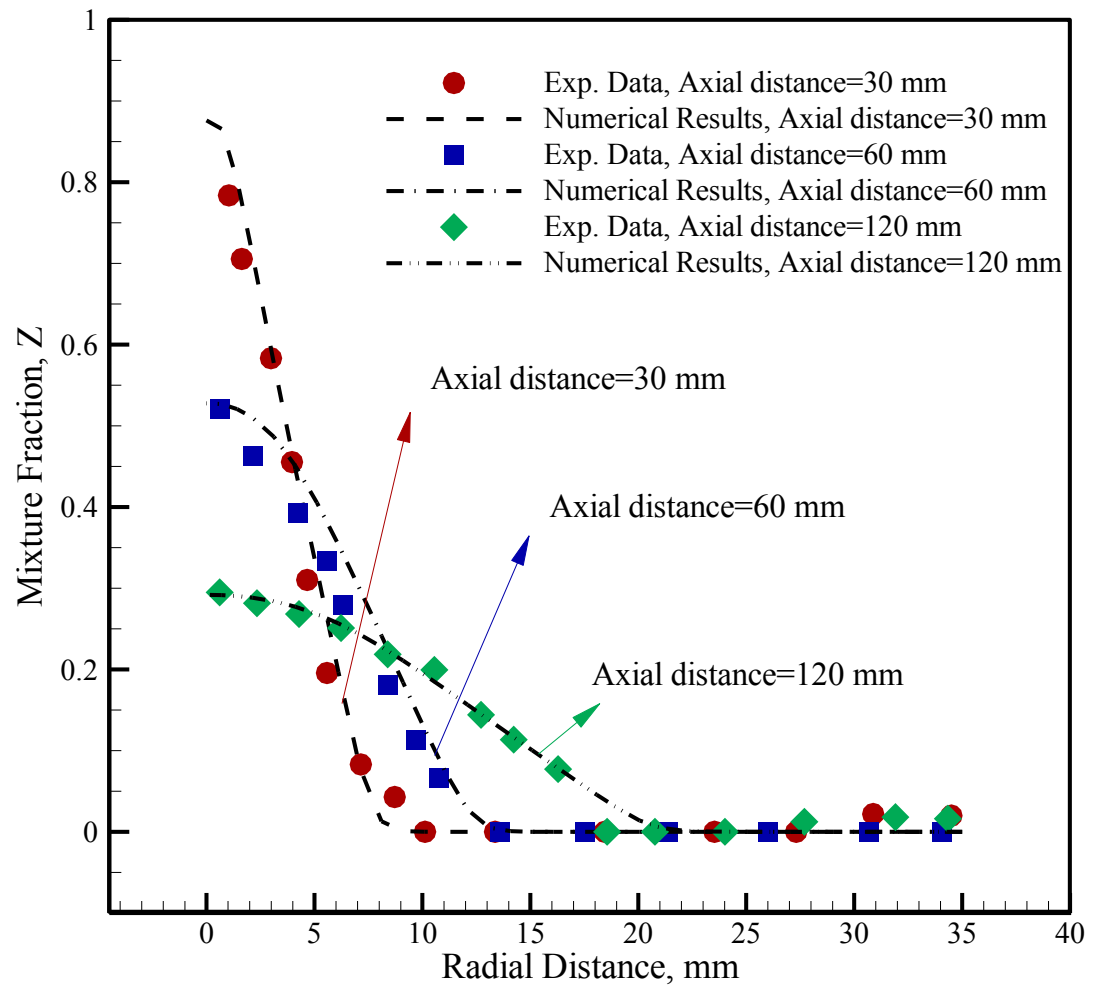

Figure 3. Validation of the present numerical simulation. 


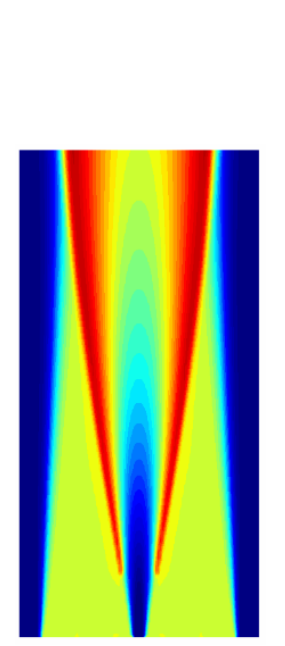

TMC

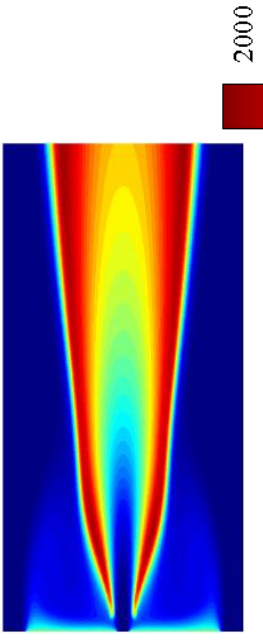

S0.8

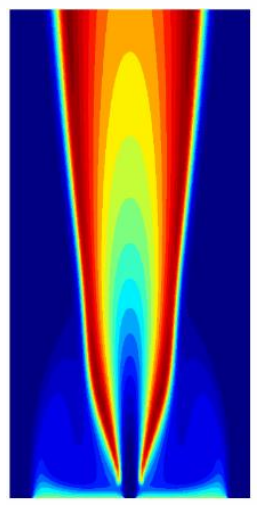

S1.6

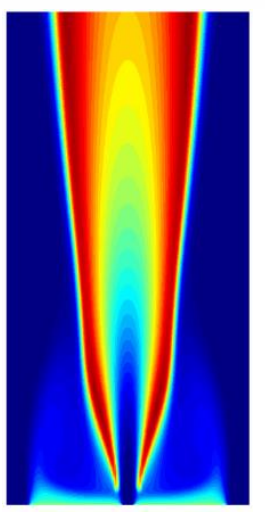

S3.2

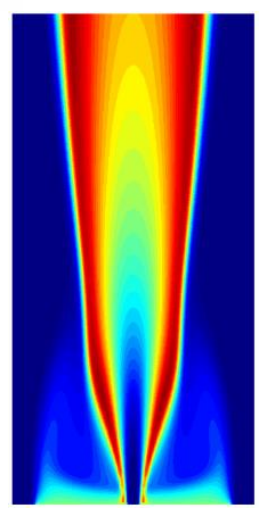

S6. 4

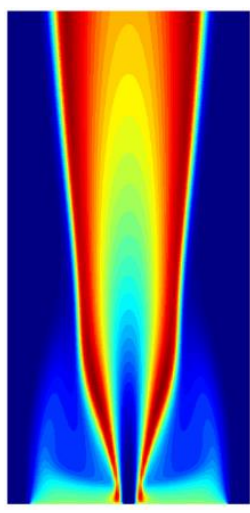

S9.6

Figure 4. Temperature distribution in TMC and swirl cases. The legend shows the flow temperature in Kelvin. 


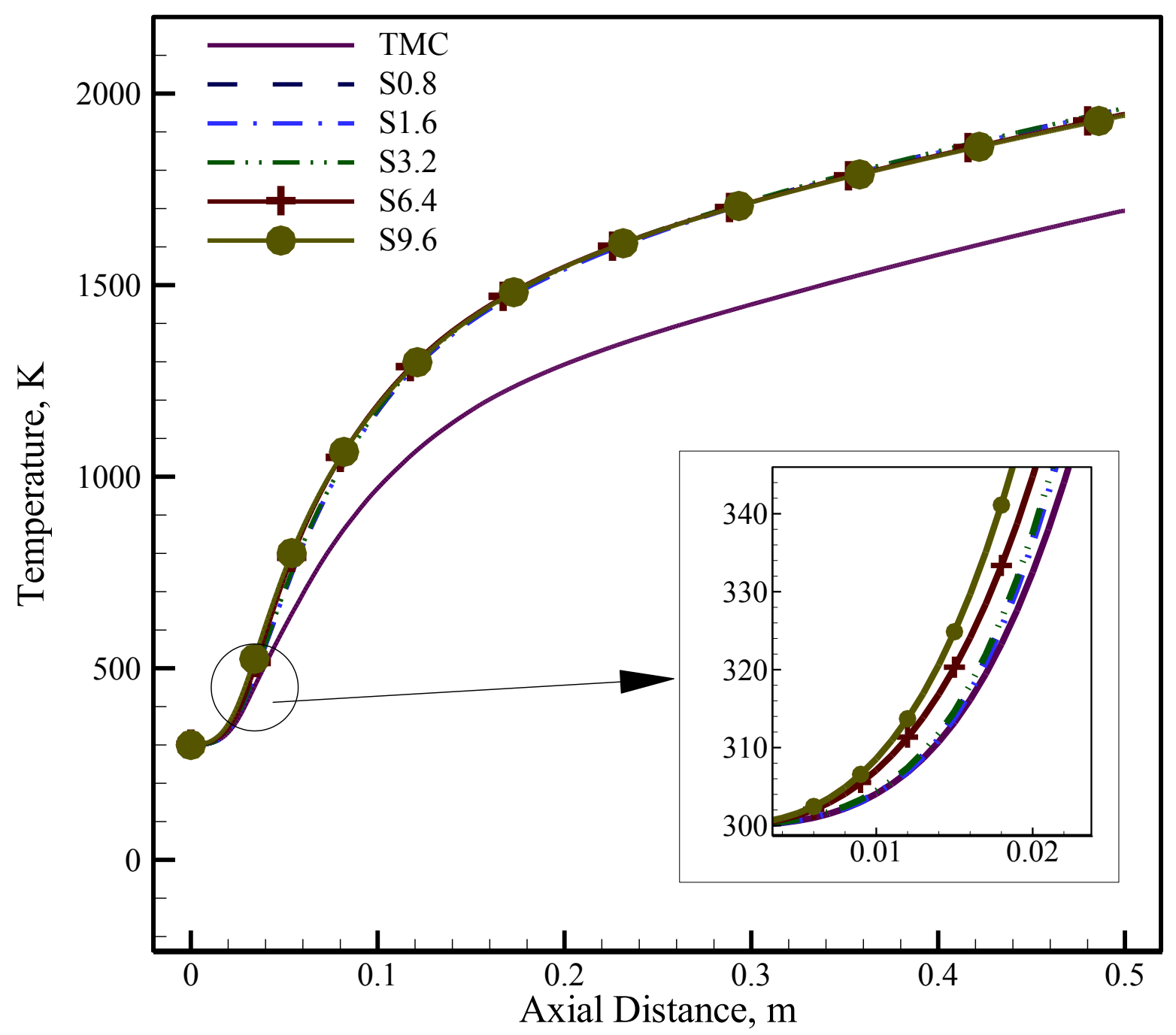

Figure 5. Axial distributions of flow temperature under TMC and swirl conditions. 

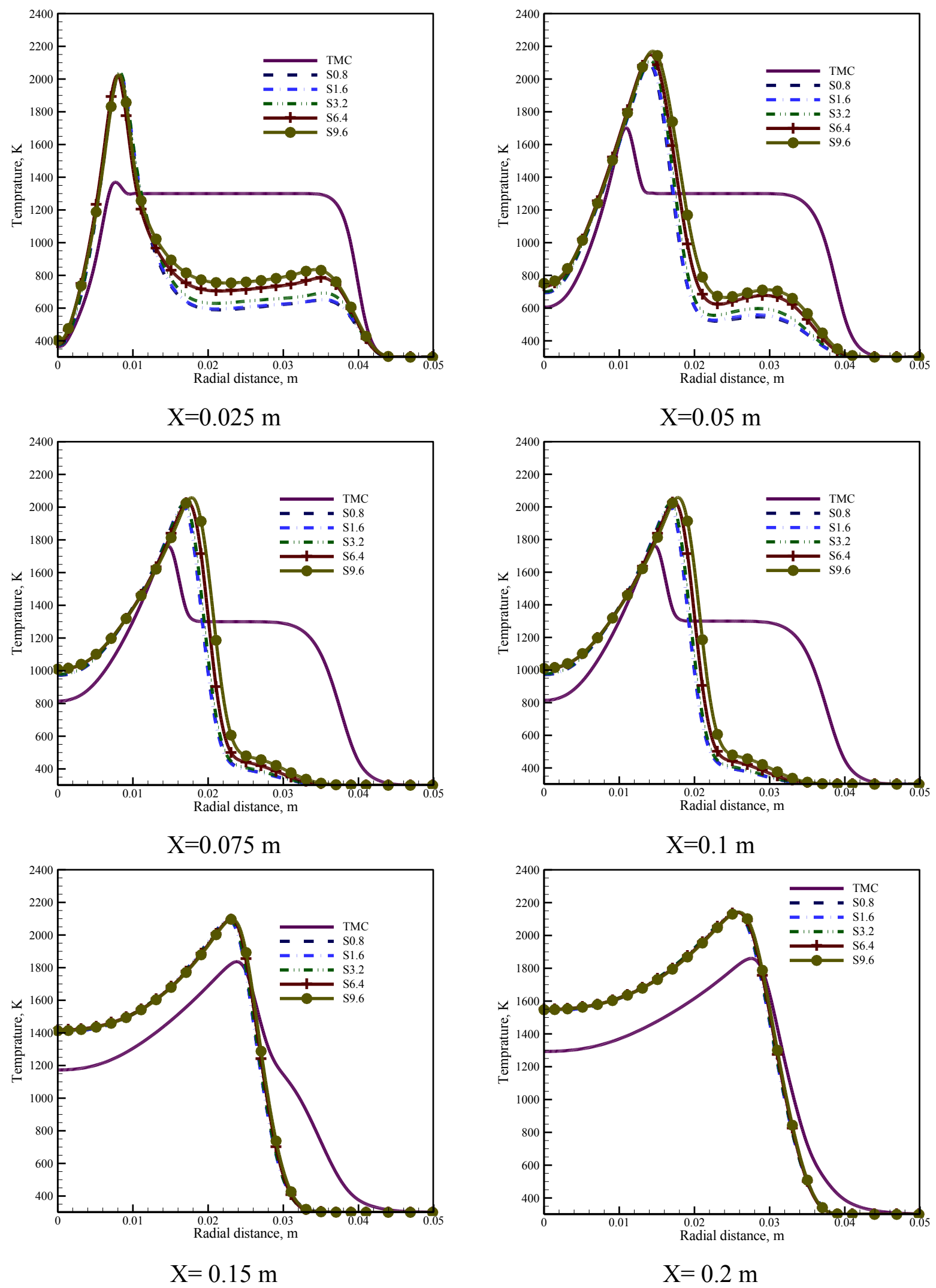

Figure 6. Radial temperature distributions at different axial locations along the burner centerline. 

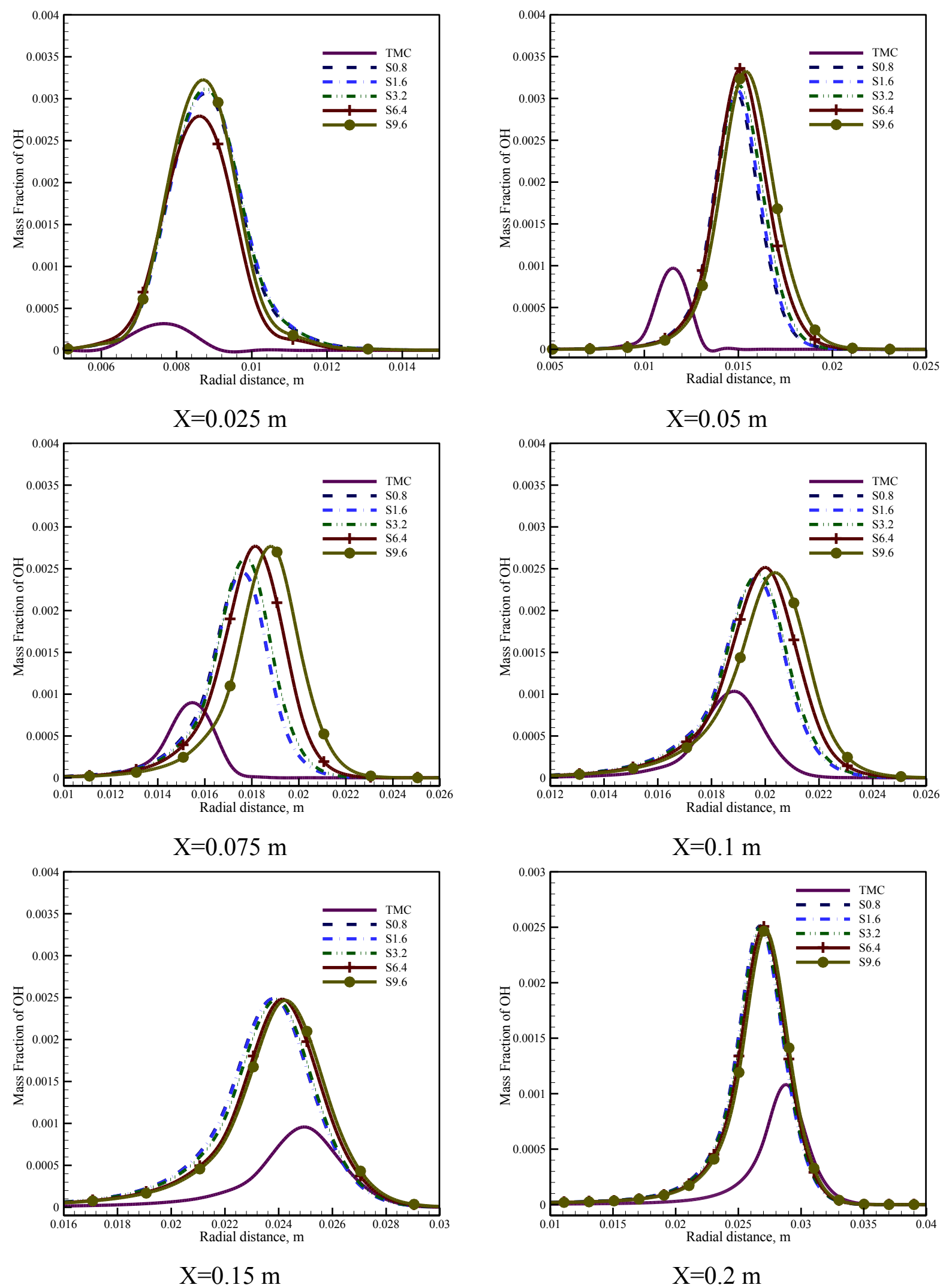

Figure 7. Radial distributions of the mass fraction of $\mathrm{OH}$ radical at different axial locations along the burner centerline. 


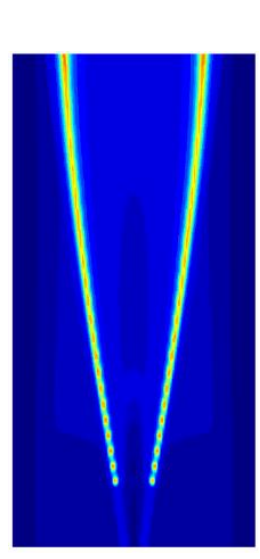

TMC

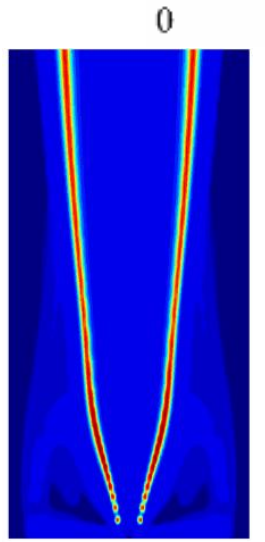

S0.8
0.0002

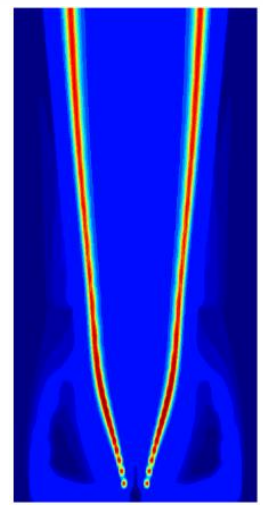

S1.6
0.0018

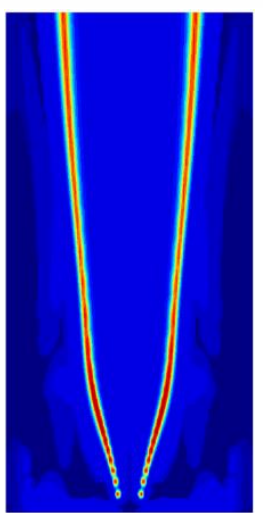

S3.2 0.0034

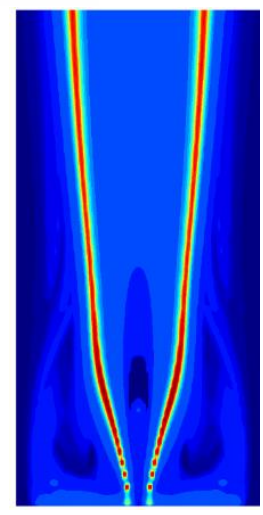

S6. 4

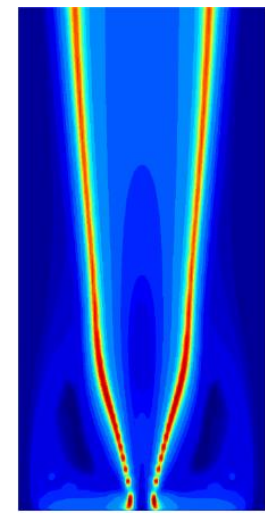

S9.6

Figure 8. Spatial distributions of the mass fraction of $\mathrm{OH}$ radical. 


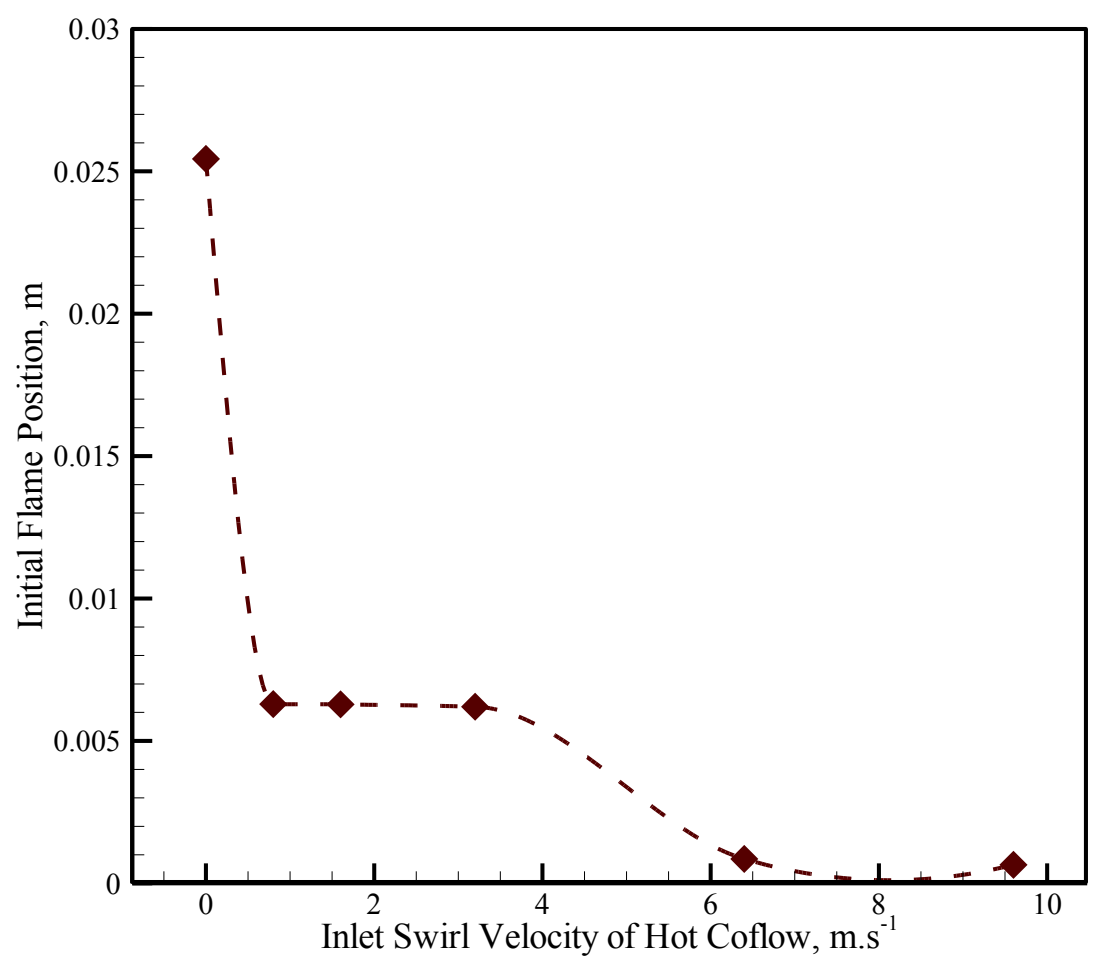

Figure 9. Axial locations of the initial reaction zone. 

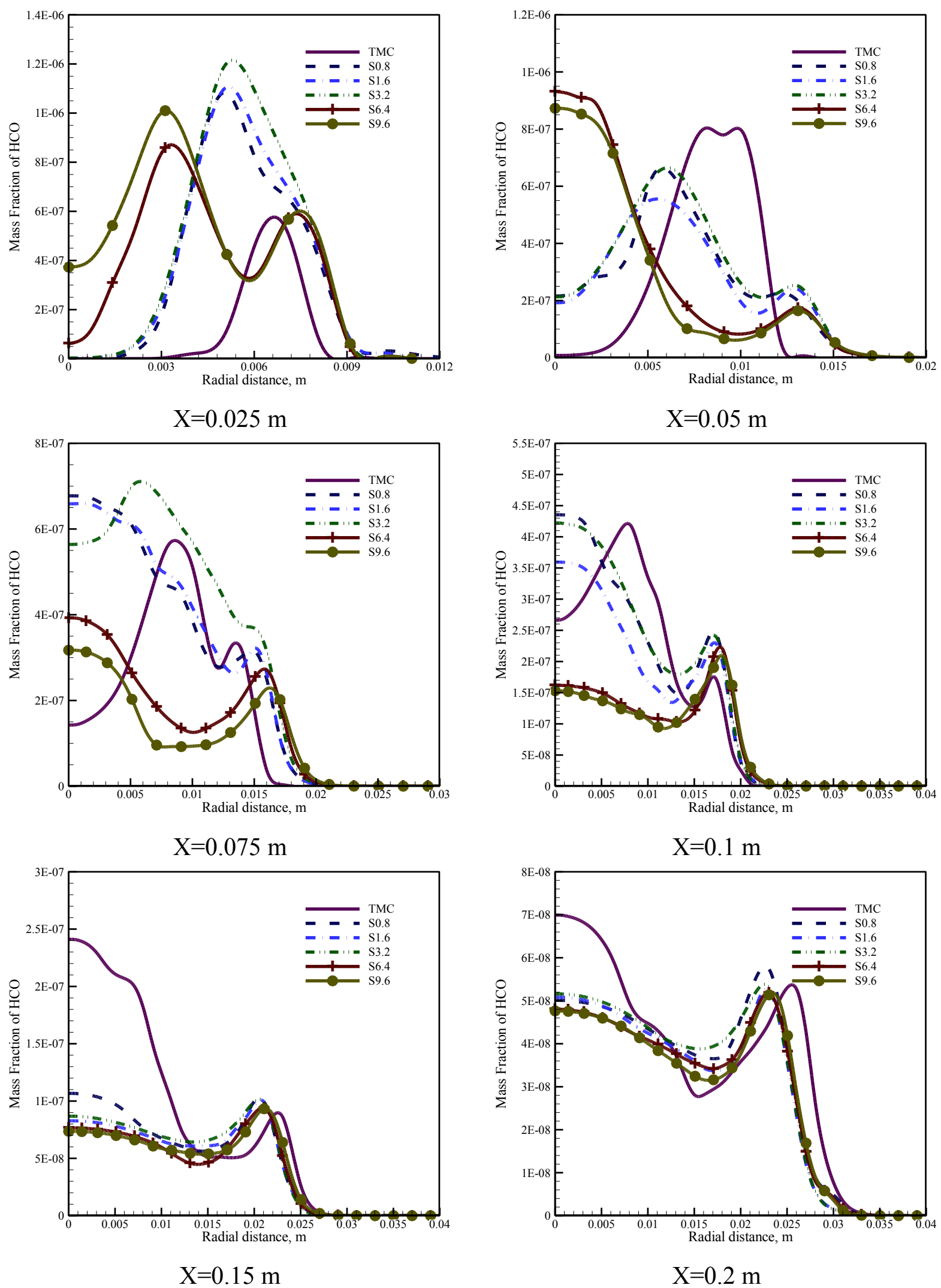

Figure 10. Distributions of the mass fraction of $\mathrm{HCO}$ radical in various axial distances. 


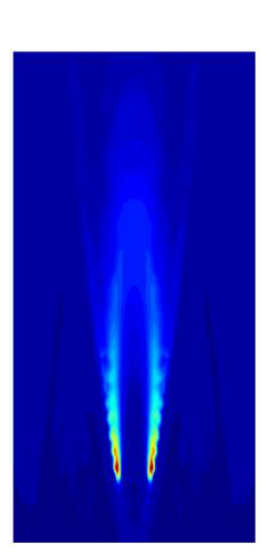

TMC

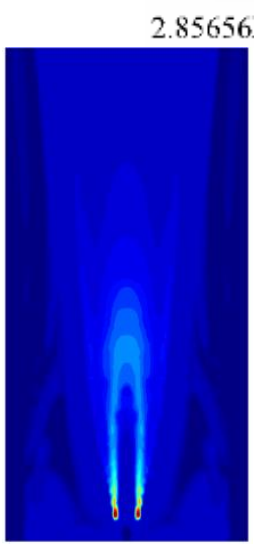

S0.8

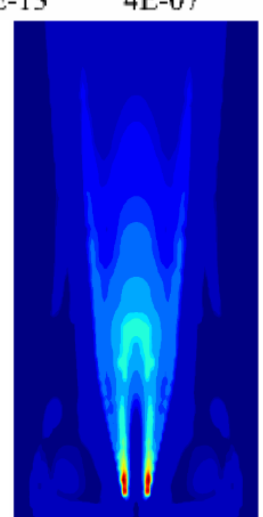

S1.6

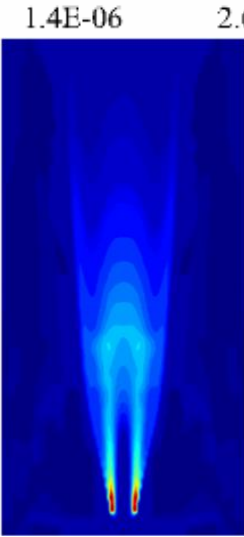

S3.2

.6E-06

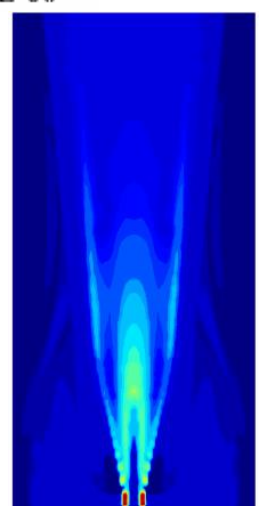

S6. 4

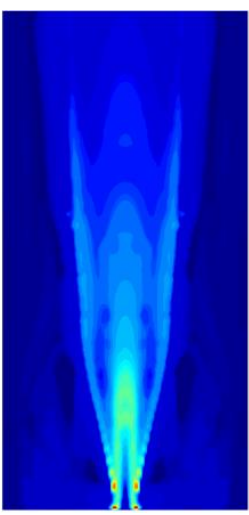

S9.6

Figure 11. Spatial distributions the mass fraction of HCO radical. 


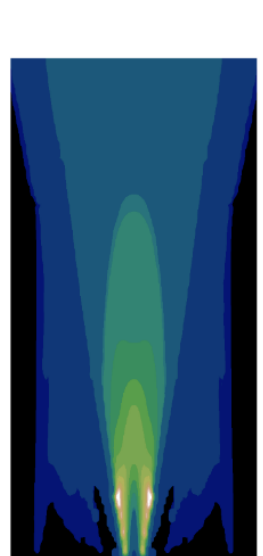

TMC

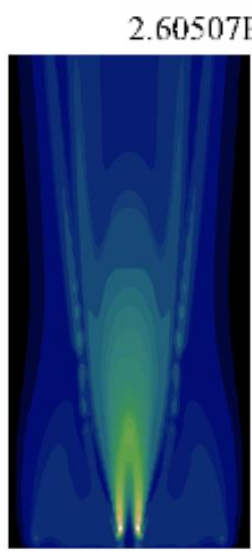

S0.8
07E-09 2.0416E-06

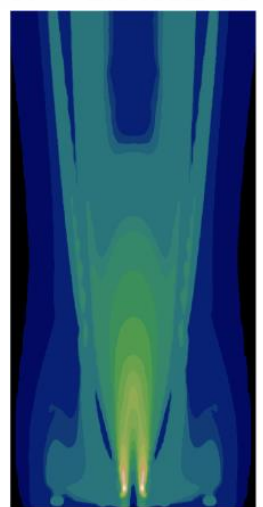

S1.6
4E-05

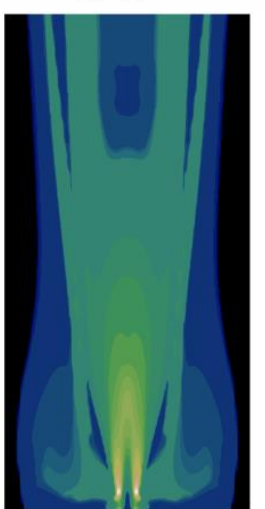

S3.2
9E-05

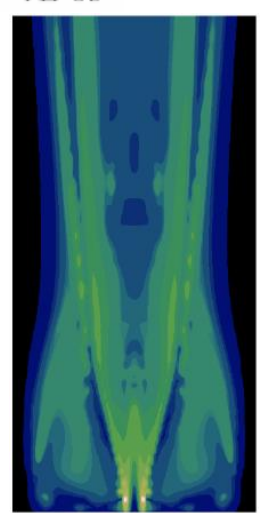

S6.4

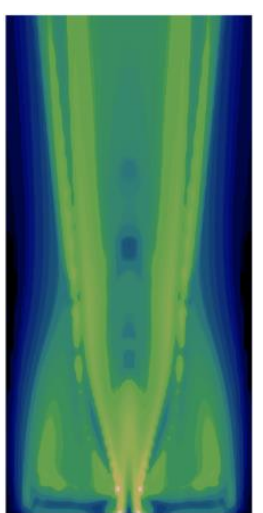

S9.6

Figure 12. Spatial distributions the mass fraction of $\mathrm{CH}_{2} \mathrm{O}$. 


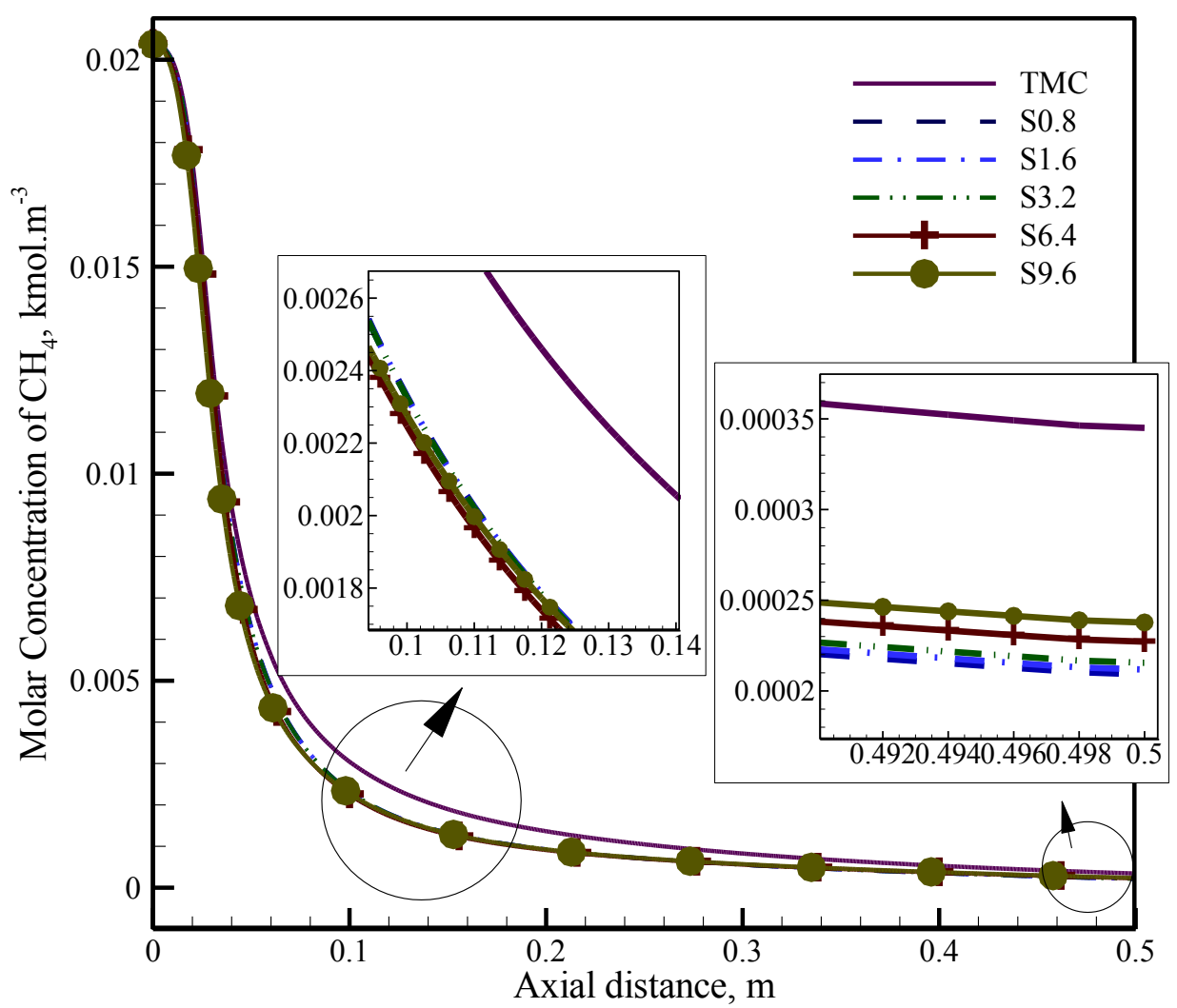

Figure 13. Axial distributions of $\mathrm{CH}_{4}$ molar concentration along the burner centerline. 

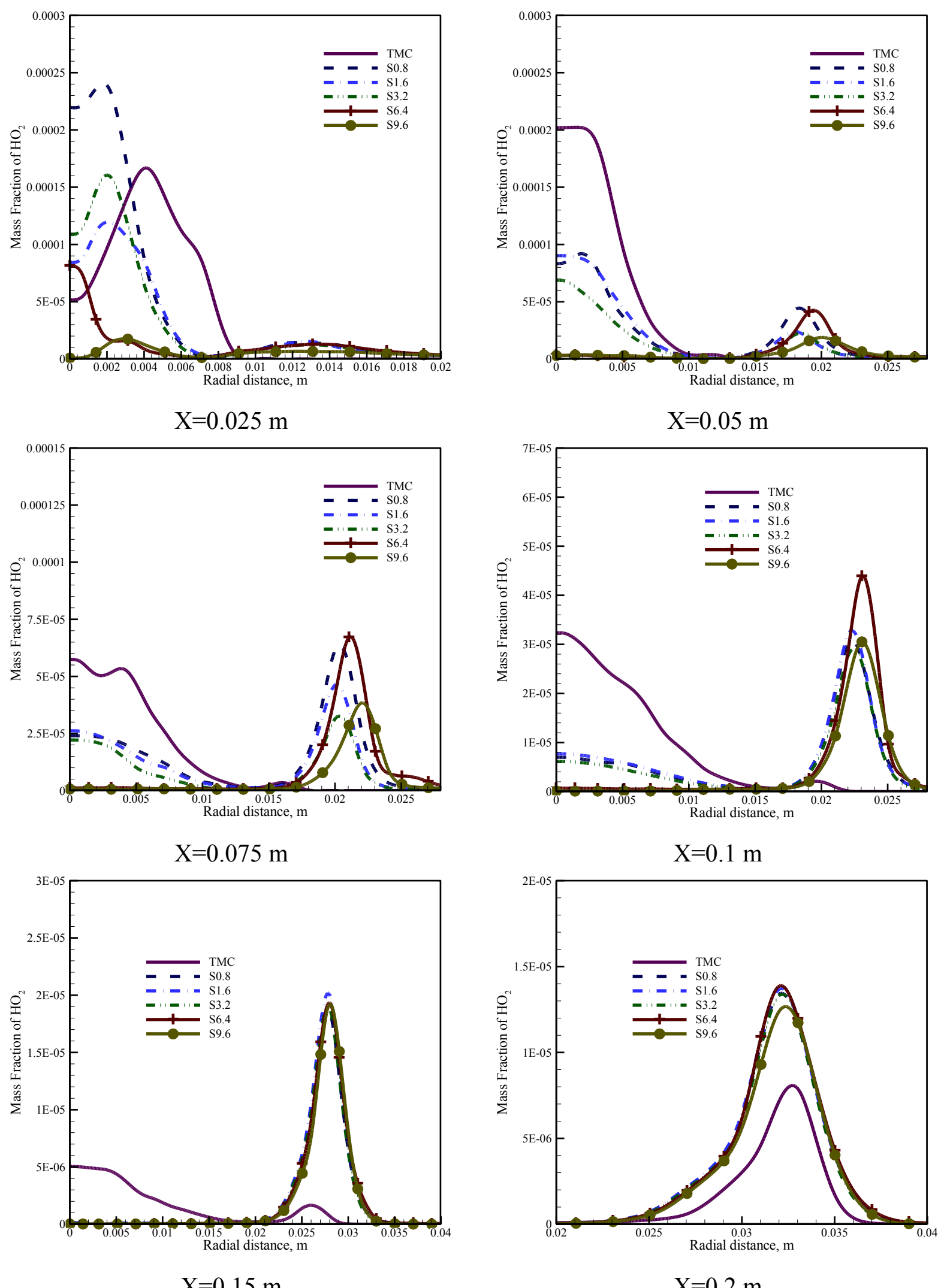

$\mathrm{X}=0.15 \mathrm{~m}$

$\mathrm{X}=0.2 \mathrm{~m}$

Figure 14. Distributions of mass fraction of $\mathrm{HO}_{2}$ radical in different axial locations. 


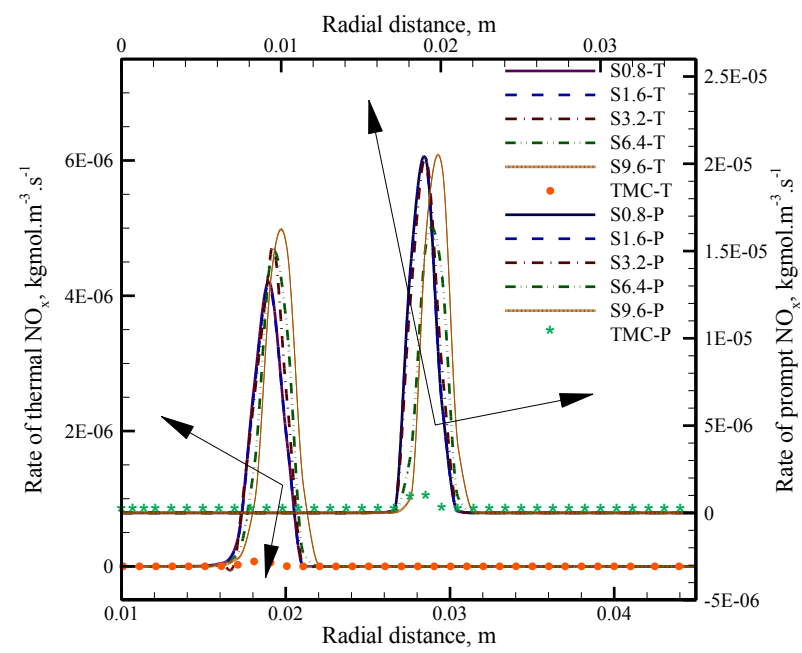

Axial distance $=0.1 \mathrm{~m}$

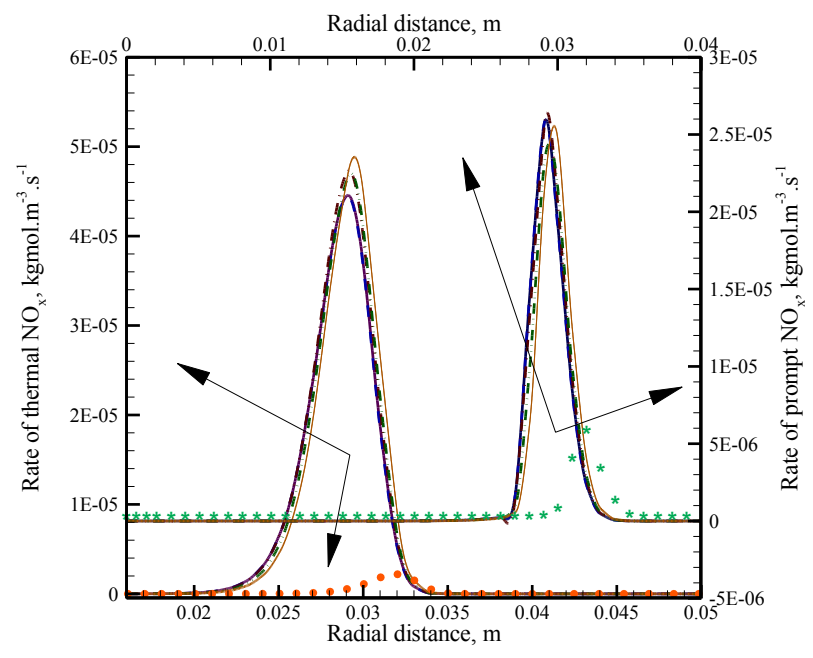

Axial distance $=0.3 \mathrm{~m}$

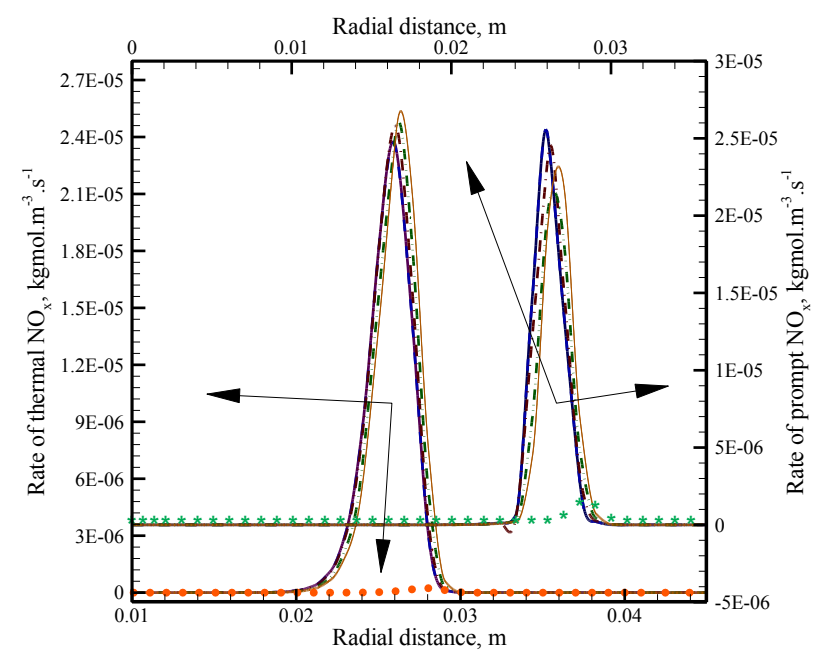

Axial distance $=0.2 \mathrm{~m}$

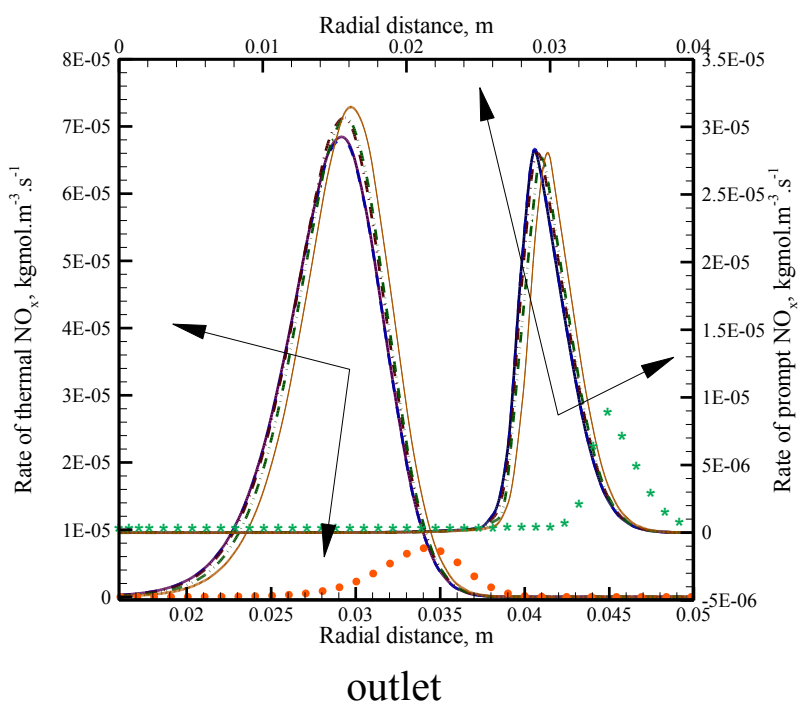

Figure 15. Thermal and prompt NO productions under swirl and TMC conditions 


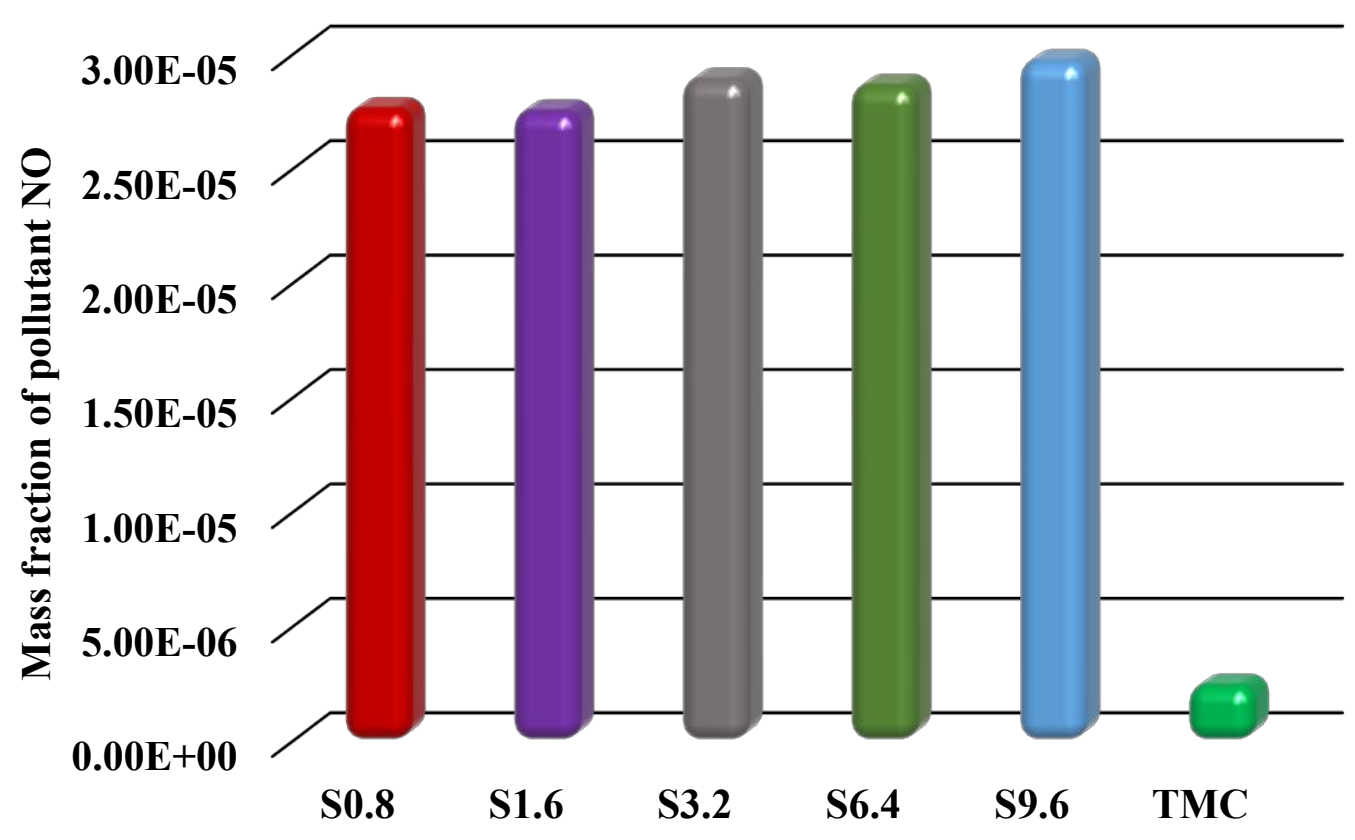

Figure 16. Average mass fraction of NO emission at the burner outlet. 


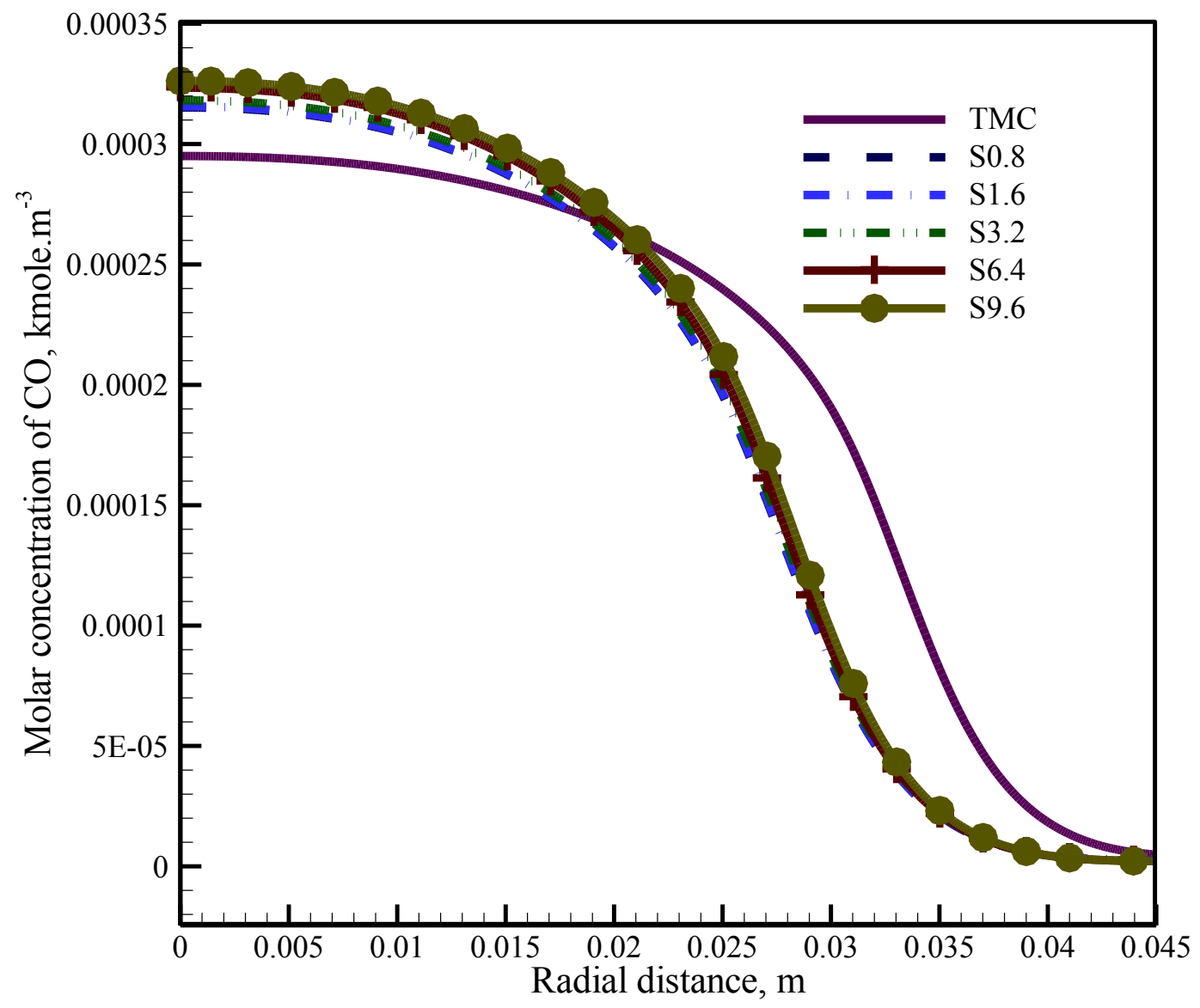

Figure 17. Radial distribution of the molar concentration of Com measured at the burner outlet $(\mathrm{x}=0.5 \mathrm{~m})$. 
Table 1. Operational conditions of the present work [45]

\begin{tabular}{|c|c|c|c|}
\hline Inlet condition & Composition, mass fraction & $\begin{array}{c}\text { Axial Velocity, } \\
\mathrm{m} / \mathrm{s}\end{array}$ & Temperature, $\mathrm{K}$ \\
\hline Fuel & $\mathrm{H}_{2}=11.1, \mathrm{CH}_{4}=88.9$ & 70 & 300 \\
\hline Coflow & $\mathrm{O}_{2}=3, \mathrm{~N}_{2}=88, \mathrm{H}_{2} \mathrm{O}=6.5, \mathrm{CO}_{2}=5.5$ & 3.2 & 1300 \\
\hline wind Tunnel & $\mathrm{O}_{2}=23.3, \mathrm{~N}_{2}=76.7$ & 3.2 & 300 \\
\hline
\end{tabular}


Table 2. Hot coflow conditions

\begin{tabular}{|l|c|c|c|c|c|c|}
\hline Case & TMC & S0.8 & S1.6 & S3.2 & S6.4 & S9.6 \\
\hline Hot coflow velocity, m/s & 3.2 & 0.8 & 1.6 & 3.2 & 6.4 & 9.6 \\
\hline Swirl angular velocity, rad/s & 0 & 0.8 & 1.6 & 3.2 & 6.4 & 9.6 \\
\hline
\end{tabular}


Table 3. Reaction mechanism to product $\mathrm{HO}_{2}$ species $[54,55]$

\begin{tabular}{|c|c|}
\hline & Reactions \\
\hline 1 & $\mathrm{O}_{2}+\mathrm{CH}_{2} \mathrm{O}<=>\mathrm{HO}_{2}+\mathrm{HCO}$ \\
\hline 2 & $\mathrm{H}+\mathrm{O}_{2}+\mathrm{M}<=>\mathrm{HO}_{2}+\mathrm{M}$ \\
\hline 3 & $\mathrm{OH}+\mathrm{HO}_{2}<=>\mathrm{O}_{2}+\mathrm{H}_{2} \mathrm{O}$ \\
\hline 4 & $\mathrm{H}+2 \mathrm{O}_{2}<=>\mathrm{HO}_{2}+\mathrm{O}_{2}$ \\
\hline 5 & $\mathrm{H}+\mathrm{O}_{2}+\mathrm{H}_{2} \mathrm{O}<=>\mathrm{HO}_{2}+\mathrm{H}_{2} \mathrm{O}$ \\
\hline 6 & $\mathrm{H}+\mathrm{O}_{2}+\mathrm{N}_{2}<=>\mathrm{HO}_{2}+\mathrm{N}_{2}$ \\
\hline 7 & $\mathrm{OH}+\mathrm{H}_{2} \mathrm{O}_{2}<=>\mathrm{HO}_{2}+\mathrm{H}_{2} \mathrm{O}$ \\
\hline 8 & $\mathrm{HCO}+\mathrm{O}_{2}<=>\mathrm{HO}_{2}+\mathrm{CO}$ \\
\hline
\end{tabular}

